\title{
Terceirização como estratégia de gestão do conhecimento
}

PEDRO JÁCOME de MOURA JR.

Universidade federal da Paraíba / Departamento de AdMinistração, JoÃo Pessoa - PB, Brasil

\begin{abstract}
Resumo
Calcado na abordagem teórica da firma baseada em recursos, este estudo explora e descreve em que medida gestores optariam pela implantação e condução da gestão do conhecimento em sua organização por meio de terceirização, uma vez que reconheçam as dificuldades de realização dessa atividade só com recursos próprios. Este artigo lança mão da literatura sobre gestão do conhecimento e outsourcing (ou terceirização), procurando destacar pontos de intersecção entre as disciplinas e propõe um modelo conceitual de pesquisa que sintetiza a rationale adotada. O modelo conceitual é submetido a validação empírica específica e os resultados são analisados com o uso de comparações par a par do método determinístico de decisão com múltiplos atributos e análise de conteúdo. Entre os achados, observa-se, principalmente, homogeneidade dos respondentes quanto à disposição ao risco da gestão do conhecimento terceirizado, restrita pelo receio da perda de habilidades e competências, bem como pela inadequação do provedor em se manter atualizado. Do ponto de vista teórico, observou-se no relacionamento entre gestão do conhecimento e outsourcing uma extrapolação de conceitos sedimentados, o que pode gerar provocações sobre a assunção de que a terceirização é apropriada apenas para áreas ou funções que possam ser suficientemente roteirizadas, descritas e compartimentadas em um escopo pré-definido (em geral descritas como áreas meio). Como contribuição à prática, constatou-se entre os gestores entrevistados o reconhecimento do tema "gestão do conhecimento" como relevante processo a incorporar à rotina de gestão. Observou-se, ainda, a possibilidade de elaboração e oferta de serviços em terceirização da gestão do conhecimento, com base no modelo conceitual aqui proposto.
\end{abstract}

Palavras-chave: Terceirização. Gestão do conhecimento. Terceirização da gestão do conhecimento.

\section{Outsourcing as knowledge Management Strategy}

\section{Abstract}

Grounded in the resource-based view of the firm, this study addresses and describes to what extent managers might choose to deploy and pursue knowledge management in their organization by outsourcing, because they recognize the difficulties to fulfill this activity relying solely on their own resources. This article looks at the literature on knowledge management and outsourcing, seeking to highlight the intersection between the subjects, as well as proposing a conceptual research model that summarizes the rationale adopted. The conceptual model undergoes a specific empirical validation and the results are analyzed using peer-to-peer comparisons of the deterministic decision method with multiple attributes and content analysis. Among the findings, it was observed the homogeneity of respondents regarding the willingness of outsourced knowledge management to take risks, which is constrained in the organization by fear over loss of abilities and skills, as well as inadequacy of the provider to keep up to date. From a theoretical viewpoint, it was observed in the relationship between knowledge management and outsourcing, an extrapolation of consolidated concepts, something that may generate provocation with regard to the assumption that outsourcing is appropriate only for areas or functions that can be sufficiently scripted, described, and shared within a predefined scope (usually described as non-core areas). As a contribution to practice, it was possible managers recognize the subject "knowledge management" as a process that demands 'management' and should been introduced in their practices. Also observed was the possibility to devise and provide knowledge management outsourcing services, having the conceptual model proposed here as a basis.

Keywords: Outsourcing. Knowledge management. Knowledge management outsourcing.

\section{La externalización como estrategia de gestión del conocimiento}

\section{Resumen}

Apoyado en el enfoque teórico de la empresa basada en recursos, el estudio explora y describe en qué medida los gerentes optarían por la aplicación y conducción de la gestión del conocimiento en su organización mediante la externalización, puesto que reconocen las dificultades de llevar a cabo esta actividad sólo con recursos propios. En este artículo se hace uso de la literatura sobre gestión del conocimiento y externalización (outsourcing), que busca resaltar los puntos de intersección entre las disciplinas y propone un modelo conceptual de investigación que resume la rationale adoptada. El modelo conceptual se sometió a validación empírica específica, y los resultados se analizaron utilizando comparaciones par a par del método determinista de decisión con múltiples atributos y análisis de contenido. Entre los hallazgos se observa, principalmente, la homogeneidad de los encuestados con respecto a la disposición al riesgo de la gestión del conocimiento externalizado, restringida por el temor a la pérdida de habilidades y competencias, así como por la inadecuación del proveedor para mantenerse actualizado. Desde un punto de vista teórico, se observó en la relación entre gestión del conocimiento y externalización una extrapolación de conceptos sedimentados, lo que puede causar provocaciones sobre la presunción de que la externalización sólo es apropiada para áreas o funciones que pueden ser suficientemente planificadas, descritas y compartimentadas en un ámbito predeterminado (generalmente descrito como áreas medio). En cuanto a la contribución práctica, se constató, entre los administradores, la introducción del tema "gestión del conocimiento" como pertinente proceso a manejar. También se observó la posibilidad de desarrollar y ofrecer servicios de externalización de la gestión del conocimiento, con base en el modelo conceptual aquí propuesto.

Palabras-clave: Externalización. Gestión del conocimiento. Externalización de la gestión del conocimiento.

Artigo submetido em 9 de abril de 2015 e aceito para publicação em 29 de janeiro de 2016

DOI: http://dx.doi.org/10.1590/1679-395148416 


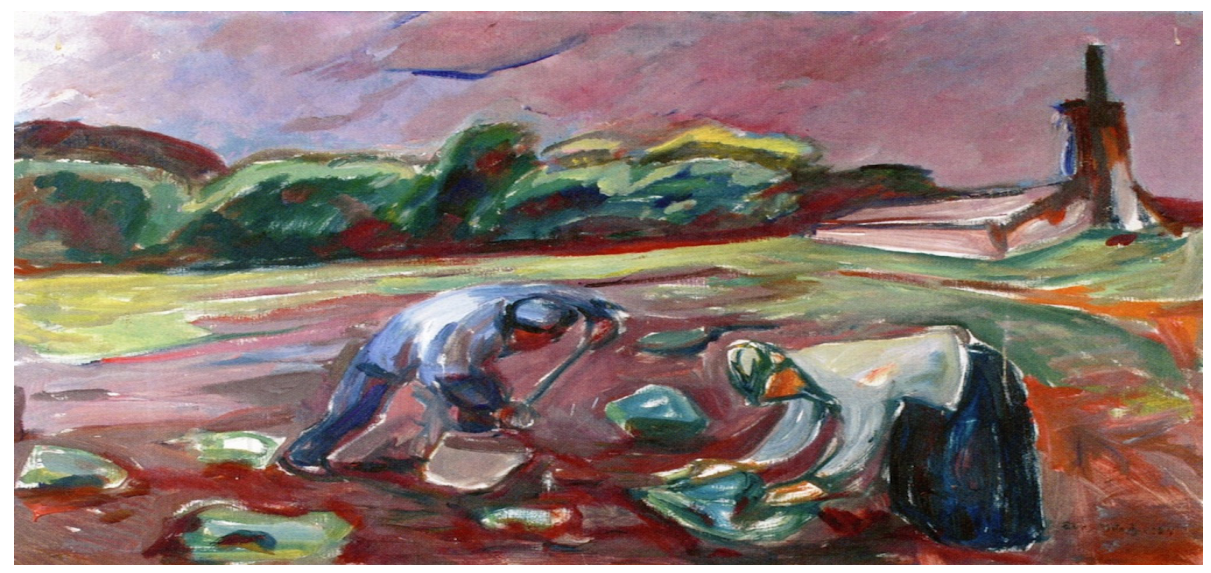

\section{INTRODUÇÃO}

O conhecimento tem sido, gradual e crescentemente, percebido por gestores como relevante para a sobrevivência de sua organização. Saber onde está o conhecimento e quem o detém, saber o que se sabe e mesmo o que não se sabe, mas que se deveria saber, são questões de ordem para empresas que valorizam a gestão do conhecimento como atividade capaz de contribuir significativamente para o desenvolvimento de capacidades organizacionais (DOSI, NELSON e WINTER, 2000). Essa relevância perpassa os níveis operacionais, táticos e estratégicos, uma vez que o emprego de processos de gestão do conhecimento pode adicionar valor considerável às operações rotineiras (aplicação de conhecimentos para solução de problemas do dia a dia), à execução de ações gerenciais e ao planejamento e direcionamento estratégico, favorecendo a inovação em todos os níveis e, por fim, garantindo à organização vantagens competitivas sustentadas (SADEGHI, MOGHIMI e RAMEZAN, 2013).

Não obstante, há dificuldades consideráveis ao se tentar gerir conhecimentos. Pesquisas apontam que muitas empresas reconhecem que o conhecimento necessário ao desenvolvimento de suas capacidades existe na organização, mas identificá-lo, encontrá-lo e alavancá-lo permanece um problema (ALAVI e LEIDNER, 2001; OLIVEIRA, CALDEIRA e ROMÃO, 2012; DIEDRICH e GUZMAN, 2015). Evidências mostram que até $84 \%$ das iniciativas de implantação da gestão do conhecimento falham ao não apresentar resultados relevantes (LUCIER e TORSILIERI, 1997; AMBROSIO, 2000), enquanto as causas dessas falhas são atribuídas a isolamento funcional, falta de participação, recusa em compartilhar informações e falhas nos sistemas de gestão do conhecimento (IDM, 2015).

Investigam-se as causas dos fracassos, discutem-se os fatores de sucesso, busca-se definir quadros de referência para a implantação sistemática de programas de gestão do conhecimento, mas ainda há sensíveis dificuldades em lidar com a gestão do conhecimento nas empresas. Então, por que não procurar apoio externo? Por que não contar com o auxílio de um parceiro especializado em gestão do conhecimento? Por que não terceirizar a gestão do conhecimento? Ou seja, por que não terceirizar os processos de implantação e de gestão (condução da gestão) do conhecimento?

Embora tradicionalmente a prática da terceirização tenha-se concentrado em atividades não relacionadas ao core business organizacional, observa-se em algumas organizações (o que poderia ser) o início de movimento de flexibilização dessa premissa, com iniciativas de terceirização de atividades consideradas estratégicas (LACITY e WILLCOCKS, 2013; EDVARDSSON e DURST, 2014). Este estudo procura avaliar em que medida gestores sem experiência em gestão do conhecimento optariam pela implantação e condução da gestão do conhecimento em sua organização (uma atividade central, por pressuposto) por meio de empresas terceirizadas. Definido um modelo conceitual de pesquisa específico, busca-se responder à questão: é

\footnotetext{
* Fonte da imagem: Edvard Munch, 1924. At Work by the Greenhouse. Disponivel em: http://www.the-athenaeum.org/art/detail.php?ID=91828. Acesso em
} 26 abr. 2017. 
possível que gestores optem por terceirizar a gestão do conhecimento, uma vez reconhecidas as dificuldades de realização dessa atividade apenas com recursos próprios?

Neste artigo, faz-se uso da literatura em gestão do conhecimento e em terceirização, procurando-se destacar pontos de intersecção entre as disciplinas; propõe-se um modelo conceitual de pesquisa que sintetiza a rationale adotada, entre as diversas áreas do conhecimento envolvidas; estabelece-se um desenho de pesquisa com fins à validação empírica das proposições contidas na terceirização da gestão do conhecimento; e analisam-se e discutem-se os resultados obtidos. Quanto à literatura considerada, optou-se por tratar preferencialmente aquela associada às publicações em Tecnologia da Informação (TI) e Sistemas de Informação (SI) pela proximidade do tema e do corpo teórico empregado.

Este estudo adota indistintamente os termos terceirização e outsourcing para representar a atividade de contratação de um terceiro para a execução de atividades de responsabilidade do primeiro.

\section{REFERENCIAL TEÓRICO}

\section{Conhecimento e gestão do conhecimento}

A extensiva aplicação de conhecimentos concentrada no período que antecedeu e perpassou a Segunda Guerra Mundial levou ao desenvolvimento de um campo de estudos que hoje se entende como gestão do conhecimento (PRUSAK, 2001; TAKEUCHI e NONAKA, 2008). De uma abordagem baseada em "learning by doing", as organizações passaram a gerir o conhecimento com foco para se tornarem mais eficientes (PRUSAK, 2001). No pós-guerra essa visão econômica do conhecimento é gradativamente enriquecida com posicionamentos da Sociologia - para a qual o conhecimento é gerado e compartilhado em redes e comunidades -, da Psicologia, da Educação (ensino-aprendizagem ou aprendizagem organizacional) e da Filosofia, que atribuem ao homem papel singular no domínio do conhecimento, colocando suas motivações para aprender, esquecer, agir, ignorar, falhar ou colaborar à frente, em ordem de importância, dos processos de mera transferência do conhecimento entre pessoas e repositórios, ou vice-versa (ARGYRIS, 1977; KAKABADSE, KAKABADSE e KOUZMIN, 2003). Esse processo elevou o status de componentes da gestão do conhecimento, como julgamento, liderança e inovação, o que passou a denotar uma tendência de visão centrada no conhecimento para as empresas (GRANT, 1996; PRUSAK, 2001).

No entanto, não é possível avançar na discussão sobre o conhecimento sem discutir, mesmo que de maneira simplificada, sua natureza. De forma geral, o conhecimento requer informação e a informação requer dados, embora esses conceitos não sejam intercambiáveis (DAVENPORT e PRUSAK, 1998). A despeito das diferentes definições de dado, informação e conhecimento (ALAVI e LEIDNER, 2001), assume-se, neste estudo, que dado é um fragmento bruto da realidade (VIEIRA, 1999), que por si não oferece um entendimento completo sobre determinado fenômeno (dessa realidade) e pode ser representado por símbolos como números, letras ou palavras. Um dado não permite um julgamento ou uma interpretação direta dos fatos. A informação, por sua vez, é o dado processado e dotado de significado. O conhecimento seria, por sua vez, a informação tácita ou explícita aplicada, mais próximo da ação do que os dados ou as informações, e capaz de explicar a produtividade organizacional (GRANT, 1996; DAVENPORT e PRUSAK, 1998; PRUSAK, 2001; NONAKA e KROGH, 2009). Essa visão plenamente objetivada de conhecimento, no entanto, não está isenta de crítica. Conhecimento como objeto, passível, portanto, de identificação, classificação, coleta, armazenamento etc., privilegia aspectos tecnológicos do conhecimento em detrimento de aspectos sociais (FLEURY e OLIVEIRA JR., 2001). Ocorreria, em casos assim, desequilíbrio entre os subsistemas social (pessoas e estruturas) e técnico (tecnologia e tarefas) em sistemas de trabalho fundamentados em uma abordagem sociotécnica (TRIST, 1993).

Em perspectiva mais próxima da abordagem sociotécnica, o conhecimento pode ser interpretado como processo, consequência de interações entre indivíduos, ocorridas durante suas atividades na organização em que atuam (SPENDER, 2001). Nessa perspectiva, o estímulo às interações se sobrepõe à preocupação com a objetivação do conhecimento. É o fluxo de interações que promove a criatividade nas equipes de trabalho e, por sua vez, que influencia a organização para que modifique a si e ao ambiente em que se insere (NONAKA, TOYAMA e HIRATA, 2008). 
O conhecimento nesse nível pode ser classificado como frônese (phronesis) que, segundo Aristóteles, seria "a capacidade de determinar e executar a melhor ação em uma situação específica" (NONAKA, TOYAMA e HIRATA, 2008, p. 14). A frônese distingue-se de outras formas de conhecimento, como episteme, que seria o conhecimento objetivo e independente de contexto, ou techne, a habilidade prática requerida para a execução-criação. A frônese seria então a sabedoria prática, equivalente ao conhecimento tácito (POLANYI, 1966) adquirido pelo indivíduo ao longo de sua experiência de vida e que se manifesta como "conhecimento-na-ação" ou "reflexão-na-ação" (POLANYI, 1966, p. 82).

Em uma organização baseada no conhecimento as pessoas são o principal ativo, porque só uma cultura - no sentido mesmo do que cultiva - pode desenvolver: a) o senso coletivo de valorização do conhecimento; b) as interações necessárias à emergência do fluxo criativo transformador; e c) a sabedoria prática que favorece a reflexão-na-ação (POLLACK, 2012; ASIEDU, 2015). É a gestão desse conhecimento que dará à organização não só sua caracterização unívoca, mas também diferenciação no ambiente de atuação, o que se traduz em condições favoráveis ao desenvolvimento de vantagens competitivas, consoante à visão da firma baseada em recursos (RBV) (CONNER e PRAHALAD, 1996) e sua extensão, a abordagem da firma baseada em conhecimentos (GRANT, 1996).

Importa ressaltar que persiste discussão ontoepistemológica quanto às perspectivas positivista e construtivista/interpretativista a respeito do conhecimento (GRANT, 1996; SPENDER e SCHERER, 2007; O'BRIEN, 2015). Na perspectiva positivista, Grant (1996), por exemplo, defende que a abordagem da firma baseada em conhecimentos é uma extensão da RBV, ao passo que na perspectiva construtivista, Spender e Scherer (2007) defendem que a abordagem da firma baseada em conhecimentos é, por definição, distinta da RBV. Considerando-se que uma discussão que envolva perspectivas ontológicas e epistemológicas demanda, per se, extensa e profunda fundamentação (o que foge ao escopo deste trabalho), opta-se, neste estudo, por tratar a abordagem da firma baseada em conhecimentos como extensão da RBV, entendendo-se que esse posicionamento não afeta seu enquadramento ontoepistemológico, nem as demais etapas da pesquisa.

O gerenciamento do conhecimento nas organizações refere-se à identificação e à promoção do conhecimento coletivo, apoiando assim a competitividade organizacional pela capacidade de inovar e dar respostas aos desafios do dia a dia (ALAVI e LEIDNER, 2001; LIEBOWITZ e MEGBOLUGBE, 2003). A gestão do conhecimento é percebida como um conjunto de práticas organizacionais que estruturam e facilitam o aprendizado e o compartilhamento de conhecimentos (FERGUSON, HUYSMAN e SOEKIJAD, 2010). Gerir conhecimento requer, com alguma variação na sequência de passos, atuação contínua em atividades de criação, captura, refinamento, armazenamento, gerenciamento, disseminação, utilização e mensuração de conhecimentos (DEMAREST, 1997; DAVENPORT e PRUSAK, 1998; AHMED, LIM e ZAIRI, 1999; ARMISTEAD, 1999; BURK, 1999; FONSECA, 2003; BOSE, 2004; GOLDONI e OLIVEIRA, 2007; DALKIR, 2011).

A gestão do conhecimento é inserida na organização por meio de um processo de implantação, que deve atender a um setor ou área organizacional onde o conhecimento seja reconhecidamente de alto valor. Idealmente, a gestão do conhecimento deve ser implantada sem se perder de vista fatores culturais, técnicos, organizacionais, econômicos, processuais, comunicativos, motivacionais e estruturais (DAVENPORT e PRUSAK, 1998), ou seja, implica visão holística da organização e do papel do conhecimento. Essa implantação toma por base um modelo de referência, ou um framework, que orienta, em um primeiro momento o processo de inserção e, posteriormente, ajuda a conduzir de forma bem-sucedida a gestão do conhecimento (WONG e ASPINWALL, 2004). A literatura sobre o tema descreve variados modelos de gestão do conhecimento, cada um tratando de especificidades de uma área ou de um setor produtivo, e atendendo a perspectivas ontológicas e epistemológicas também específicas sobre o conhecimento em si (KAKABADSE, KAKABADSE e KOUZMIN, 2003; FONSECA, 2006).

Uma taxonomia compreensiva dos modelos de tratamento do conhecimento foi desenvolvida por Kakabadse, Kakabadse e Kouzmin (2003), denominada Quantum KM Model, que mapeia as diversas perspectivas existentes, e por vezes conflitantes, de análise da gestão do conhecimento. Esses autores descrevem quatro modelos de gestão do conhecimento: a) de base filosófica; b) de comunidades; c) de rede; e d) cognitivo. Os modelos empregam, respectivamente, um enfoque voltado à epistemologia do conhecimento, ou o que constitui o conhecimento e como pode ser entendido e aplicado como elemento da visão estratégica; um enfoque histórico-sociológico, baseado em comunidades de prática, assumindo que o conhecimento existe enquanto flui entre as pessoas em coletividade; um foco na crença de que indivíduos agem motivados por interesses sociais e econômicos e que essas ações são influenciadas pelas redes de relacionamento em que estão inseridos; e um enfoque no conhecimento como um ativo valioso e estratégico, sustentado pela tradição positivista em 
ciência, na qual o conhecimento pode ser aplicado na solução de problemas e na exploração de oportunidades (KAKABADSE, KAKABADSE e KOUZMIN, 2003).

Com base na perspectiva cognitiva, pode-se resumir as componentes de um efetivo programa de gestão do conhecimento em três grandes grupos de questões: pessoas, processos e tecnologia (FONSECA, 2003). Apesar de diferentes terminologias e classificações de conceitos adotados, essas três componentes estão presentes na literatura da gestão do conhecimento com, no máximo, alguma variação em seus arranjos, mesmo que o equilíbrio entre as componentes não tenha sido observado, o que conduz a esforços contraprodutivos na busca da transformação do conhecimento em ação. Para suprir a lacuna existente, o World Bank Institute (WBI) criou um método de diagnóstico da gestão do conhecimento intitulado Organizational Knowledge Assessment (OKA). O diagnóstico com o OKA consiste em avaliar as capacidades que a organização detém para gerir seu capital intelectual, segundo parâmetros que consideram pessoas, processos e tecnologia (FONSECA, 2006).

No modelo OKA, esses três elementos são constituídos por catorze dimensões de conhecimento, caracterizadas por métricas definidas e traduzidas em questões que, juntas, formam o instrumento de levantamento de dados para diagnóstico da gestão do conhecimento. O elemento "pessoas" é composto pelas dimensões "cultura e incentivos", "criação e identificação de conhecimentos", "compartilhamento de conhecimentos", "comunidades de prática e equipes de conhecimento" e "aprendizagem e absorção de conhecimento". "Processos" é composto pelas dimensões "estratégia e liderança", "fluxo de conhecimentos", "operacionalização de conhecimentos", "alinhamento aos objetivos da organização" e "medição e monitoramento". "Tecnologia" é composto pelas dimensões "infraestrutura tecnológica para gestão do conhecimento", "infraestrutura de acesso ao conhecimento", "gerenciamento de conteúdos" e "infraestrutura de suporte ao programa de gestão do conhecimento" (FONSECA, 2006). Pode-se inferir que o método OKA adota elementos da abordagem sociotécnica (TRIST, 1993) sem, no entanto, contemplar - explicitamente - a dimensão "estrutura" do subsistema social.

Justifica-se que um framework para a construção de uma organização baseada no conhecimento não prescinde de uma consciência, de uma taxonomia e de uma estratégia de gestão do conhecimento, o que implica necessariamente a atuação de pessoas; da mesma forma, requer-se a seleção de ferramentas e infraestrutura apropriadas, o que pode ser interpretado como tecnologia de apoio à gestão do conhecimento; e, por fim, destaca-se a necessidade de sistemas, processos e práticas (LIEBOWITZ e MEGBOLUGBE, 2003), o que reforça a aplicabilidade das dimensões OKA na construção do modelo de avaliação da opção pela gestão terceirizada do conhecimento. Além disso, as catorze dimensões OKA compreendem atividades de criação, captura, refinamento, armazenamento, gerenciamento, disseminação, utilização e mensuração de conhecimentos, conforme explicitado no Quadro 1.

\section{Quadro 1}

\section{Associação das atividades da gestão do conhecimento e dimensões OKA}

\begin{tabular}{|c|c|}
\hline $\begin{array}{c}\text { Atividades da gestão do } \\
\text { conhecimento }\end{array}$ & Dimensões OKA \\
\hline Criação & Identificação e criação \\
\hline Captura & Identificação; infraestrutura de acesso ao conhecimento \\
\hline Refinamento & Gerenciamento de conteúdos \\
\hline Armazenamento & Tecnologia de Informação de suporte; infraestrutura de suporte \\
\hline Gerenciamento & Liderança e estratégia; Incentivos; Alinhamento \\
\hline Disseminação & Compartilhamento \\
\hline Utilização & Aprendizado e absorção \\
\hline Mensuração & Medição e monitoramento \\
\hline
\end{tabular}

Fonte: Adaptado de Fonseca (2003).

Embora um conjunto das atividades envolvidas na gestão do conhecimento, bem como as suas respectivas definições, seja imprescindível à implantação de um programa de gestão do conhecimento, há aspectos não menos importantes que, no entanto, não são incluídos em termos de atividades, como apresentado no Quadro 1. Trabalhando sobre esses aspectos, 
Malhotra (2004) os denomina "facilitadores e restrições" relacionados à gestão do conhecimento, explicitados na forma de sete desafios: estratégia de negócios e de tecnologia; controle organizacional; cultura de compartilhamento da informação; representação do conhecimento; estrutura organizacional, controle e comando gerencial; e retorno econômico. Uma forma alternativa de considerar os aspectos que facilitam e os que dificultam a gestão do conhecimento é observá-los como fatores que levam ao sucesso e fatores que levam ao fracasso, respectivamente.

Os estudos em gestão do conhecimento têm primado pela pesquisa dos fatores de sucesso (DAVENPORT e PRUSAK, 1998; RUGGLES, 1998; WONG, 2005) e as causas dos insucessos (RUGGLES, 1998; MALHOTRA, 2004; 2005; LAM e CHUA, 2005) das iniciativas de implantação, o que acabou por desenvolver uma literatura consistente sobre o tema que tem servido de referência para pesquisas na área, não obstante as possíveis críticas a respeito dos enfoques e das abordagens adotadas. Para Davenport e Prusak (1998), há nove fatores principais de sucesso em projetos de implantação da gestão do conhecimento: cultura orientada ao conhecimento; infraestrutura técnica e organizacional; suporte aos gerentes sêniores; vínculos com valores econômicos da indústria da qual participa a organização; orientação a processos; claridade de visão e linguagem; incentivos motivacionais não triviais; nível mínimo de estrutura de conhecimentos e múltiplos canais de transferência de conhecimentos.

Em contrapartida, as causas dos fracassos, segundo Lucier e Torsilieri (1997), envolvem: inexistência de um objetivo específico de negócios; arquitetura incompleta para o programa; foco insuficiente em uma ou duas prioridades estratégicas; e envolvimento insuficiente dos gestores do topo.

\section{Terceirização}

A busca por vantagens competitivas faz com que organizações considerem estrategicamente a delegação da responsabilidade pela execução de funções a terceiros (SOUZA, MALDONADO e RADOS, 2011). O fato de esses "terceiros", caracterizados doravante neste estudo simplesmente como provedores, serem capazes de oferecer economia de escala, conhecimento especializado e tecnologia atualizada, entre outros recursos desejáveis, é que tem posto a terceirização em destaque nas últimas décadas como prática adotada nos mais diversos setores da atividade econômica (HÄTÖNEN e ERIKSSON, 2008).

O outsourcing como estratégia corporativa surgiu na década de 1950, mas só veio a se tornar prática estratégica na década de 1980 (LACITY e HIRSCHHEIM, 1993) com as primeiras terceirizações de serviços em operações não pertencentes ao core business organizacional, como call centers (HÄTÖNEN e ERIKSSON, 2008). Daí em diante, a delegação de funções de negócio (business process outsourcing, BPO), de gestão da TI (information technology outsourcing, ITO), de processos legais (legal process outsourcing, LPO), de relacionamentos com clientes (customer process outsourcing, CPO) e de processos de uso intensivo do conhecimento (knowledge process outsourcing, KPO), por exemplo, a provedores externos terceirizados, passou a ser uma prática comum e crescente (CULLEN, SEDDON e WILLCOCKS, 2005; HÄTÖNEN e ERIKSSON, 2008; SOUZA, MALDONADO e RADOS, 2011; KALAIGNANAM e VARADARAJAN, 2012; LACITY e WILLCOCKS, 2013).

De acordo com relatório produzido pela International Data Corporation (IDC), o mercado mundial de outsourcing, só em TI, representou US\$ 240,2 bilhões em 2006 (LEE, 2008). Em 2011 esse valor superou US\$ 246 bilhões (GARTNER, 2013), o que sugere estabilidade (em relação à medição anterior, de 2006), mesmo em período pós-crise econômica mundial ocorrida em 2008. No momento, o número de novos contratos de terceirização, em nível global e em diversas indústrias (não apenas em TI), supera as expectativas nos dois primeiros quadrimestres de 2015 (ISG, 2015). Esses indicadores ilustram motivos da atenção que tem sido dada, pela academia e pelo mercado, ao tema.

Estudos sobre terceirização concentram-se em quatro grandes temas, de acordo com Hätönen e Eriksson (2008): a) por que as empresas optam por "comprar" em vez de "fazer", tema que se baseia firmemente nas teorias do custo de transação (TCT); b) o que as empresas optam por terceirizar, tema calcado na noção das competências centrais, tal qual posto por Hamel e Prahalad (1990); c) onde as empresas escolhem seus provedores, que trata o fenômeno da localização geográfica do terceiro; e, por fim, d) como as empresas terceirizam, o que envolve questões referentes ao gerenciamento dos relacionamentos entre a empresa contratante e o provedor.

Subjacente aos temas se encontram as teorias que dão lastro às explicações do fenômeno "outsourcing": além da TCE, já citada, a RBV, a teoria dos sistemas, a teoria da internalização, a teoria da agência, a network theory, as teorias de evolução e aprendizagem organizacionais, a teoria da dependência de recursos e a teoria da troca social que "captam os diferentes 
aspectos deste fenômeno simultâneo" (HÄTÖNEN, ERIKSSON, 2008, p. 148) e é essa diversidade teórica que implica necessidade de visão abrangente do fenômeno, para que não se incorra em reducionismos (GOO, KISHORE, NAM et al., 2007; HÄTÖNEN e ERIKSSON, 2008; SOLLI-SAETHER e GOTTSCHALK, 2008).

Ao adotar-se perspectiva abrangente para análise do fenômeno terceirização, observa-se insuficiência do conceito de cadeia de valor - como definido por Porter (1985) - para tratar a conversão de valor de origem intangível (conhecimento ou reputação, por exemplo) em criação de valor para a organização, dificuldade que pode ser superada por meio do conceito de redes de valor (LEE, 2008). Redes de valor expandem o conceito de cadeias de valor ao contemplarem relacionamentos e atributos de valor que emergem das interações entre as componentes da rede (BUSBIN, JOHNSON e DeCONINCK, 2008). Nessa perspectiva, as organizações contratante e provedora compõem nós de uma rede que integra processos (que poderiam ser considerados centrais a cada nó), capaz de criar valor que dificilmente poderia ser criado por cada organização, isoladamente.

Empiricamente, já se observam estratégias de terceirização de processos centrais que são importantes na criação de valor (EDVARDSSON e DURST, 2014). É o caso, por exemplo, da terceirização de processos legais (legal process outsourcing, LPO), relatado por Lacity e Willcocks (2013), ou terceirização de pesquisa e desenvolvimento (research and development, R\&D), relatado por Martinez-Noya, Garcia-Canal e Guillen (2013). Estratégias de terceirização nesses níveis têm levado ao desenvolvimento de uma área de negócios denominada terceirização de processos de conhecimento (knowledge process outsourcing, KPO) que enseja investigação acadêmica (EDVARDSSON e DURST, 2014) também com o intuito de identificar os fatores de sucesso e os de fracasso.

O sucesso da terceirização está fundamentado em decisões do contratante referentes à medida em que as funções são terceirizadas, à duração do trabalho em outsourcing e ao tipo do relacionamento adotado (KALAIGNANAM e VARADARAJAN, 2012; EDVARDSSON e DURST, 2014). Assim, a estratégia de terceirização é a lógica visível em um portfólio de decisões de outsourcing na empresa. É a manifestação observável de múltiplas decisões (LEE, MIRANDA e KIM, 2004).

Em relação à medida em que as funções são terceirizadas, iniciativas de outsourcing podem ser categorizadas como compreensiva, seletiva ou mínima. Essa gradação da atividade terceirizada baseia-se no percentual do orçamento de TI que está sendo terceirizado, com as seguintes frações: mínima, abaixo de $20 \%$; seletiva, entre $20 \%$ e $80 \%$; e compreensiva, com $80 \%$ ou mais do orçamento (LACITY e WILLCOCKS, 2013; LEE, MIRANDA e KIM, 2004).

A duração do trabalho representa o tempo total de relacionamento entre um contratante e um provedor em atividades terceirizadas (GOO, KISHORE, NAM et al., 2007) e é categorizada como de curto (menos de quatro anos), médio (entre quatro e sete anos) e longo prazo (mais de sete anos), e, independentemente da perspectiva estratégica adotada, os contratos de longo prazo superam os de curto prazo e, em algumas situações, superam também os de médio prazo (LEE, MIRANDA e KIM, 2004).

Baseados na teoria do direito residual (GROSSMAN e HART, 1986), Lee, Miranda e Kim (2004) propõem três possíveis configurações próprias de estratégias: abordagem hierárquica, de mercado e incorporada (independent, arm's length ou network, nos respectivos termos originais em inglês). A abordagem hierárquica pressupõe relacionamentos tênues, em que os recursos são contratados externamente e gerenciados internamente, com o intuito de reduzir a dependência do provedor externo. Na abordagem de mercado, os relacionamentos são objetivos, a responsabilidade sobre eventuais obrigações não especificadas fica a cargo do provedor e compromissos de longo prazo são evitados para aumentar a eficiência de custos mediante preços competitivos. Por fim, a abordagem incorporada busca relacionamentos sociais próximos e de longo prazo, em que os vínculos pessoais e a confiança que deles emerge promovam níveis de governança suficientes para substituição de declarações formais em contrato (LEE, MIRANDA e KIM, 2004). Esta última assertiva é corroborada por Solli-Saether e Gottschalk (2008) quando tratam de um modelo de maturidade em outsourcing de TI: a existência de relacionamentos relativamente íntimos pode reduzir a necessidade de monitoramento detalhado do desempenho do provedor pelo contratante.

Mas, por que terceirizar? Aceitando a explicação de Lacity e Willcocks (2013), entende-se que as empresas almejam eficiência de custos, desenvolvimento de competências centrais, catálise de sua base tecnológica, apoio durante as etapas de transição de negócios, acesso e estímulo à inovação e a abertura e conquista de novos mercados, como fatores, individuais ou combinados, para que optem pela terceirização de parte de suas funções organizacionais.

Subjacente a tais razões estão os benefícios esperados com a prática da terceirização. Gonzalez, Gasco e Llopis (2010) elaboraram um conjunto de sete motivos pelos quais se julga válido o outsourcing: 1) foco na estratégia organizacional, como uma 
das principais maneiras de fazer com que a organização dirija seus esforços para suas competências essenciais; 2) aumento de flexibilidade, em que se adota a terceirização durante reestruturações e reorganizações internas de processos; 3 ) facilidade de acesso à tecnologia, quando a terceirização contribui para a redução da necessidade de investimentos em tecnologia e aumenta a disponibilidade de novas tecnologias para a contratante; 4) redução do risco de obsolescência, uma vez que o risco de prospecção e investimento em novas tecnologias é do provedor, pois há necessidade de atualização constante nessas novas tecnologias também; 5) redução de custos com staff - seleção, contratação, capacitação constante e eventuais demissões ficam a cargo do provedor; 6) redução dos custos com tecnologia, já que expertise, habilidades e toda a infraestrutura necessária à operação terceirizada vêm com o provedor; e 7) modismo/tendências, que podem ser descritos como mecanismos miméticos em relação a outras empresas, previamente bem-sucedidos em suas experiências de terceirização. A relação de motivos é estendida por Willcocks (2010), com a sugestão (aos gestores) de mudança na agenda das funções terceirizadas em direção ao atendimento de questões estratégicas da organização.

Em contrapartida, os riscos inerentes à delegação de responsabilidades não devem ser negligenciados (PALVIA, 1995; EARL, 1996). As iniciativas de outsourcing, envolvendo funções de TI ou outros processos de negócio, continuam a gerar expectativas, enquanto impõem constantes desafios para as organizações (CULLEN, SEDDON e WILLCOCKS, 2005). Entre os desafios estão os riscos que, embora não ocorram em todas as situações de terceirização, também não são incomuns. No entanto, se a avaliação dos resultados com a terceirização versus os riscos envolvidos forem desfavoráveis, haverá uma tendência à terceirização apenas das funções consideradas commodities (EARL, 1996; TEIRLINK, DUMONT e SPITHOVEN, 2010). Earl (1996) identificou a existência de onze tipos de riscos na terceirização, o que seria um contraponto à crescente literatura prescritiva em terceirização.

Gonzalez, Gasco e Llopis (2010) atualizaram o conjunto de riscos envolvidos na prática do outsourcing: 1) dependência do provedor: dificuldade que o contratante tem de identificar, definir e quantificar os serviços necessários; 2) estagnação do provedor: a evolução necessária na área terceirizada é negligenciada, em parte porque o provedor externo não é parceiro estratégico e tende a se preocupar com o próprio lucro, mais do que com o sucesso do contratante; 3) perda de habilidades e competências críticas: mesmo quando o provedor oferece serviços inovadores para o contratante, boa parte dos novos conhecimentos permanece com o provedor; 4) qualificação insuficiente do staff do provedor: risco de se manter a qualificação de pessoal nos mesmos níveis anteriores à terceirização; 5) falhas do provedor no cumprimento do contrato: má interpretação de prioridades, prazos ou foco; 6) dificuldade do contratante em acompanhar os custos e os benefícios da terceirização: dificuldade em gerar métricas de monitoramento e custos obscuros, decorrentes de especificações falhas, turnover, mudança de provedor, gerenciamento da terceirização e insourcing dos serviços; 7) questões de segurança: negociação de níveis de confidencialidade a serem mantidos pelo provedor; 8) irreversibilidade da decisão de terceirização: o contratante perde sua infraestrutura técnica e humana para a realização do serviço; 9) problemas relacionados ao staff do contratante: a terceirização é percebida como uma ameaça aos empregos; e 10) falta de habilidade do provedor para se adaptar a novas tecnologias: o esforço para a atualização tecnológica não é recompensado e o provedor procura manter a tecnologia e os processos sem evolução.

\section{Modelo conceitual de pesquisa}

Considerando-se que a verificação empírica da opção pela gestão terceirizada do conhecimento envolveria gestores que não teriam experiência em gestão do conhecimento, haveria a necessidade de vinculação de aspectos específicos de um programa de gestão do conhecimento ao modelo conceitual de avaliação da opção pela gestão terceirizada do conhecimento, ora proposto. Assim, as catorze dimensões OKA foram incorporadas ao modelo, pois, embora concebido para adoção no diagnóstico da condição atual da gestão do conhecimento em uma organização, entende-se que o modelo OKA pode emprestar a este estudo suas componentes e dimensões, já que são suficientemente abrangentes para descrever as áreas organizacionais tratadas durante a implantação de um programa de gestão do conhecimento, não se prestando exclusivamente a aspectos de diagnóstico.

Com base no pressuposto de que o conhecimento é um recurso inerente a cada organização (GONZÁLEZ, JOAQUí e COLLAZOS, 2009) e considerando os fatores de sucesso de Davenport e Prusak (1998), as sugestões de Willcocks (2010) e as causas de insucesso de Lucier e Torsilieri (1997), este estudo contempla seletivamente as perspectivas filosófica, de comunidade e de rede, e enfatiza compreensivamente a perspectiva cognitiva (KAKABADSE, KAKABADSE e KOUZMIN, 2003) de gestão do conhecimento. 
A respeito da medida em que as funções são terceirizadas, optou-se por estender o percentual do orçamento de TI ao percentual da dimensão da gestão do conhecimento terceirizada. A duração do trabalho foi considerada no modelo de avaliação aqui proposto, incorporada à direção estratégica das funções terceirizadas, como uma medida da expectativa de duração por parte dos gestores, externada como questão aberta aos gestores.

Por prover relacionamentos sociais aproximados e de longo prazo, o que facilita a aquisição e transferência de conhecimentos, o gerenciamento dos relacionamentos baseado em network (LEE, MIRANDA e KIM, 2004) mostrou ser o mais adequado para a proposta aqui investigada. Não bastante, Willcocks (2010) sugere aos gestores que adotem uma mudança na agenda das funções terceirizadas (de TI, no caso), movimentando-se de uma abordagem tática, do tipo arm's length, em direção a uma abordagem estratégica, do tipo network. Tendo essa definição como pressuposto, a dimensão do gerenciamento dos relacionamentos não compôs, como construto, o conjunto de questões formadoras do modelo de investigação proposto (Figura 1).

Embora modismo/tendências não tenham sido um dos motivos validados empiricamente por Gonzalez, Gasco e Llopis (2010), optou-se por preservar essa razão para a terceirização, por ser um item que tem chamado a atenção. Ver como exemplo a proliferação de certificações ISO (International Organization for Standardization) concedidas sem o correspondente reflexo na qualidade percebida de produtos e serviços certificados, o que pode denotar investimentos em certificação por modismo ou tendência das empresas de um determinado setor (GOTZAMANI e TSIOTRAS, 2002).

Figura 1

\section{Modelo conceitual de pesquisa}

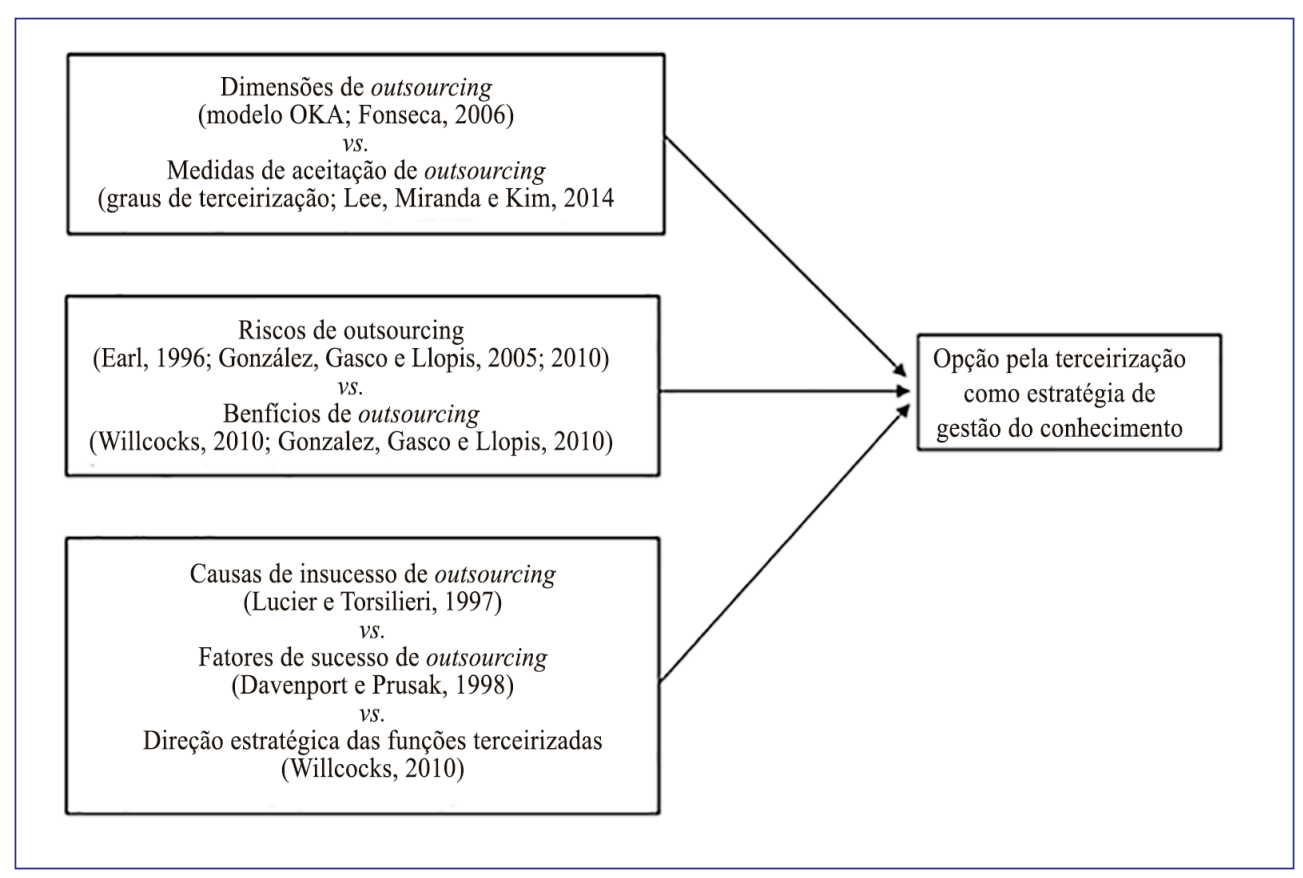

Fonte: Elaborada pelo autor.

\section{MÉTODO}

Tratando-se de pesquisa exploratória sobre os níveis de aceitação de uma ideia proposta que envolve questões estratégicas para as organizações, optou-se por selecionar respondentes que exercem cargos de nível compatível com a proposta e têm capacidade de influir nas decisões em sua organização. Assim, foram selecionados quatro gestores atuantes em organizações distintas: gerente de tecnologia da informação (GTI) de software-house desenvolvedora de soluções Enterprise Resource Planning (ERP) para a área de saúde suplementar no país; diretor de planejamento (DP) de empresa de serviços 
em marketing e publicidade, atuante no estado da Paraíba (PB); diretor de logística (DL) para a América Latina e Caribe de indústria de equipamentos elétricos, com sede em São Paulo (SP); e gerente comercial (GC) de empresa distribuidora de alimentos para a Região Nordeste do país.

Para obter dos respondentes sua percepção quanto ao nível de opção pela atuação de um provedor nas atividades de gestão do conhecimento, optou-se por entrevistas semiestruturadas, divididas em dois momentos distintos: a) preenchimento de formulários específicos e b) resposta oral a questões feitas oralmente pelo pesquisador.

Os formulários específicos, em número de dois, procuraram cobrir os relacionamentos entre os construtos considerados mais apropriados, para os fins desta pesquisa, identificados na revisão da literatura sobre outsourcing e gestão do conhecimento. O Formulário I se propõe a medir a opção pela atuação do provedor, com base nos graus de terceirização referenciados em Lee, Miranda e Kim (2004), em cada uma das dimensões da gestão do conhecimento tratadas pelo modelo OKA, de Fonseca (2006). O Formulário II implementa proposta de medição da percepção de cada um dos riscos confrontada com cada um dos benefícios de uma terceirização da gestão do conhecimento, baseado nos riscos do outsourcing descritos em Earl (1996) e González, Gasco e Llopis (2005; 2010) e nas razões para o outsourcing tratadas em Willcocks (2010) e González, Gasco e Llopis (2010).

Usando elementos do método determinístico de decisão com múltiplos atributos (MADM) descrito por Triantaphyllou, Shu, Nieto et al. (1998), o Formulário II implementou comparações par a par de forma que o respondente pudesse declarar forte ou fraca preferência por uma das duas opções (risco ou benefício do outsourcing), associando um "peso" relativo ou um fator de importância ao quesito em avaliação, à medida que sua preferência se aproximasse ou se afastasse dos limites da escala de verificação apresentada. Esse método se mostra especialmente conveniente quando um problema de tomada de decisão apresenta grande número de alternativas (TRIANTAPHYLLOU, SHU, NIETO et al., 1998). Os demais elementos do método, como a construção e o processamento da matriz de decisão, não foram aplicados neste estudo.

Ambos os formulários (ver apêndices) contêm glossário próprio, descrevendo os conceitos abordados em linguagem coloquial, embora sua aplicação não prescinda da participação dos pesquisadores, uma vez que se busca a certificação de que o entendimento dos conceitos pelos respondentes corresponde ao esperado e o preenchimento do instrumento segue estritamente as instruções fornecidas (e observadas in loco) pelo(s) pesquisador(es) aplicador(es).

As questões abertas foram elaboradas tomando-se por base as causas de insucesso das iniciativas de gestão do conhecimento relatadas por Lucier e Torsilieri (1997), os fatores de sucesso encontrados em Davenport e Prusak (1998) e os papéis da alta gestão (CEO) quanto ao redirecionamento estratégico das funções terceirizadas (WILLCOCKS, 2010) e foram elaboradas com o pressuposto da presença de um pesquisador para sua leitura e eventual esclarecimento, se necessário. Às questões elaboradas com base na literatura referenciada, adicionaram-se três perguntas consideradas pertinentes: a primeira questiona a experiência da empresa do respondente com atividade(s) terceirizada(s). O pressuposto aqui é que se já houve experiência(s) com terceirização, passa a ser relevante a obtenção de um descritivo dessa(s) experiência(s); a segunda questiona a intenção de insourcing, uma vez evidenciados os benefícios do conhecimento para a organização, por meio da experiência consumada de terceirização da gestão do conhecimento; e a terceira faz uma provocação aos respondentes sobre sua disposição em colocar sua organização em um teste piloto de terceirização da gestão do conhecimento.

A interpretação das respostas às questões abertas adotou elementos da Análise de Conteúdo, em conformidade com Franco (2007) e Bardin (1977), por ser um conjunto de técnicas que têm como intenção a inferência, com base na percepção do pesquisador, sobre o conteúdo das mensagens analisadas, a respeito do conhecimento ali contido, considerando o contexto no qual as mensagens foram produzidas e recebidas.

Os textos, ou corpus, produzidos pela transcrição de cada um dos registros de áudio tomaram como unidade de registro (FRANCO, 2007) o "tema" contido nas sentenças de cada corpus, por expressar opiniões, expectativas ou valores dos respondentes, o que se mostra adequado aos objetivos deste estudo. Os temas identificados foram classificados quanto à categorização elaborada a priori pelo pesquisador. A codificação resultante apresentou dados quantitativos de ocorrências dos temas quanto às categorias "comentário nulo", "comentário positivo", "comentário negativo" e "comentário condicionante". A codificação foi validada por análise inter-rater (GWET, 2010) e as divergências (10,64\%) foram solucionadas com pesquisador convidado a participar desta etapa de validação. Adotou-se como método para avaliação da análise inter-rater a probabilidade conjunta de acordo (joint-probability of agreement), isto é, a quantidade de vezes que uma mesma classificação foi atribuída por cada pesquisador, atuando isoladamente, a cada sentença, dividida pelo total de sentenças (GWET, 2010). 


\section{ANÁLISE DOS DADOS}

A interpretação das respostas do Formulário I baseou-se no critério de homogeneidade das respostas, em busca de afirmação ou negação da proposta de opção pela terceirização da gestão do conhecimento. A pontuação obtida com a consolidação das respostas permite constatar homogeneidade em relação à medida de opção pela atuação do provedor, quando nenhum dos respondentes optou pela medida "Nenhuma". Mesmo sabendo que a medida "Mínima" ofereceria uma faixa de comprometimento de até $20 \%$ da dimensão com terceirização, o que contemplaria inclusive o percentual zero, este autor adicionou ao instrumento a medida "Nenhuma" para oferecer uma distinção categórica, sem margem de dúvidas, entre o que poderia estar na faixa de $0 \%$ a $20 \%$ e o que não poderia nem estar nesse nível. Dada essa possibilidade de distinção, pareceu claro que os respondentes optariam, em algum nível acima de $0 \%$, pela terceirização da gestão do conhecimento.

Observa-se, pela Tabela 1, homogeneidade ainda em relação às dimensões "cultura e incentivos" e "liderança e estratégia", nas quais os respondentes conferem opção plenamente "Seletiva", ou seja, com índices de comprometimento com a terceirização entre $20 \%$ e $80 \%$ daquelas dimensões. Dado o caráter quase pleno de terceirização da medida "Compreensiva" (acima de $80 \%$ de terceirização da dimensão), destacam-se as dimensões "medição e monitoramento" e "infraestrutura de acesso ao conhecimento" com três opiniões favoráveis. As demais dimensões obtiveram níveis variados de escolha, com maior concentração das respostas no nível "Seletivo".

Tabela 1

\section{Consolidação das respostas ao Formulário I}

\begin{tabular}{|c|c|c|c|c|c|}
\hline & & \multicolumn{4}{|c|}{ Medida de opção pela atuação de provedor } \\
\hline \multicolumn{2}{|c|}{ Dimensões da gestão do conhecimento } & Nenhuma & Mínima & Seletiva & Compreensiva \\
\hline \multirow{5}{*}{ Pessoas } & Cultura e incentivos & & & 4 & \\
\hline & Identificação e criação & & 2 & 1 & 1 \\
\hline & Compartilhamento & & 1 & 3 & \\
\hline & $\begin{array}{l}\text { Comunidades de prática e equipes } \\
\text { de conhecimento }\end{array}$ & & 1 & 3 & \\
\hline & Aprendizado e absorção & & & 3 & 1 \\
\hline \multirow{5}{*}{ Processos } & Liderança e estratégia & & & 4 & \\
\hline & $\begin{array}{c}\text { Alinhamento aos objetivos da } \\
\text { organização }\end{array}$ & & 1 & 3 & \\
\hline & $\begin{array}{l}\text { Operacionalização de processos } \\
\text { do conhecimento nos processos } \\
\text { institucionais }\end{array}$ & & 1 & 2 & 1 \\
\hline & Fluxos de conhecimento & & 1 & 3 & \\
\hline & Medição e monitoramento & & & 1 & 3 \\
\hline \multirow{4}{*}{ Tecnologias } & $\begin{array}{l}\text { Tecnologia da Informação de } \\
\text { suporte às atividades e programas } \\
\text { de gestão do conhecimento }\end{array}$ & & 1 & 1 & 2 \\
\hline & $\begin{array}{l}\text { Infraestrutura de acesso ao } \\
\text { conhecimento }\end{array}$ & & 1 & & 3 \\
\hline & Gerenciamento de conteúdos & & 1 & 1 & 2 \\
\hline & $\begin{array}{l}\text { Infraestrutura de suporte } \\
\text { ao Programa de Gestão do } \\
\text { Conhecimento }\end{array}$ & & 1 & 2 & 1 \\
\hline
\end{tabular}

Fonte: Elaborada pelo autor.

Nota: os números indicam a quantidade de respostas em cada nível/medida. 
A interpretação das respostas do Formulário II fez-se com base em adaptação do método de comparações par a par (TRIANTAPHYLLOU, SHU, NIETO et al., 1998), justificado pela complexidade de análise individualizada das matrizes 10 x 07 (dez riscos versus sete benefícios) preenchidas por respondente. Cada formulário preenchido foi submetido a um processo de agrupamento das marcações individuais MkRij (resposta R, linha i, coluna j, da matriz M, respondente k) em gráficos de linhas para interpretação visual, do ponto de vista dos riscos versus benefícios e dos benefícios versus riscos. A Figura 2 ilustra o processo de agrupamento das marcações individuais para análise de um benefício vis à vis cada um dos riscos.

Figura 2

Transformação de marcações individuais em gráfico

\begin{tabular}{|c|c|c|c|}
\hline Riscos do outsourcing & $\begin{array}{c}\text { Focar a estratégia } \\
\text { organizacional }\end{array}$ & Riscos do outsourcing & $\begin{array}{c}\text { Focar a estratégia } \\
\text { organizacional }\end{array}$ \\
\hline $\begin{array}{l}\text { Perda de habilidades e } \\
\text { competências críticas }\end{array}$ & 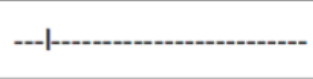 & $\begin{array}{l}\text { Perda de habilidades e } \\
\text { competências críticas }\end{array}$ & ---1 \\
\hline $\begin{array}{l}\text { Irreversibilidade da } \\
\text { decisão de terceirização }\end{array}$ & - & $\begin{array}{l}\text { Irreversibilidade da } \\
\text { decisão de terceirização }\end{array}$ & \\
\hline $\begin{array}{l}\text { Dificuldade em } \\
\text { acompanhar os custos e } \\
\text { os benefícios }\end{array}$ & 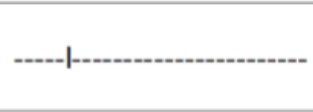 & $\begin{array}{l}\text { Dificuldade em } \\
\text { acompanhar os custos e } \\
\text { os benefícios }\end{array}$ & \\
\hline $\begin{array}{l}\text { Problemas relacionados } \\
\text { ao staff do contratante }\end{array}$ & 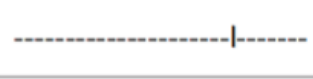 & $\begin{array}{l}\text { Problemas relacionados } \\
\text { ao staff do contratante }\end{array}$ & \\
\hline $\begin{array}{l}\text { Qualificação } \\
\text { insuficiente do staff do } \\
\text { provedor }\end{array}$ & 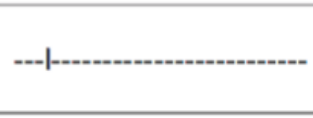 & $\begin{array}{l}\text { Qualificação } \\
\text { insuficiente do staff do } \\
\text { provedor }\end{array}$ & \\
\hline $\begin{array}{l}\text { Dependência do } \\
\text { provedor }\end{array}$ & 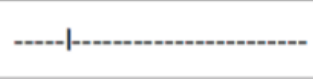 & $\begin{array}{l}\text { Dependência do } \\
\text { provedor }\end{array}$ & \\
\hline $\begin{array}{l}\text { Estagnação do } \\
\text { provedor }\end{array}$ & 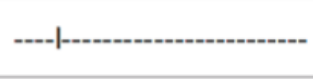 & $\begin{array}{l}\text { Estagnação do } \\
\text { provedor }\end{array}$ & \\
\hline $\begin{array}{l}\text { Falta de habilidade do } \\
\text { provedor para adaptar- } \\
\text { se a novas tecnologias }\end{array}$ & 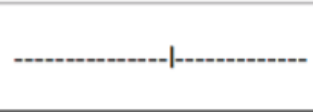 & $\begin{array}{l}\text { Falta de habilidade do } \\
\text { provedor para adaptar- } \\
\text { se a novas tecnologias }\end{array}$ & \\
\hline $\begin{array}{l}\text { Falhas do provedor no } \\
\text { cumprimento do } \\
\text { contrato }\end{array}$ & --1-1-1- & $\begin{array}{l}\text { Falhas do provedor no } \\
\text { cumprimento do } \\
\text { contrato }\end{array}$ & \\
\hline Questões de segurança & 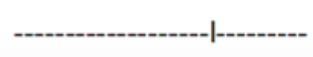 & Questões de segurança & 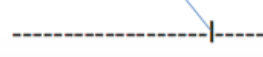 \\
\hline
\end{tabular}

Fonte: Elaborada pelo autor.

A Figura 3 ilustra o resultado obtido com a sobreposição dos gráficos para cada respondente. Do gráfico GC infere-se uma preocupação quanto à "perda de habilidades e competências críticas", "qualificação insuficiente do staff do provedor", "estagnação do provedor" e "falhas do provedor no cumprimento do contrato" perante qualquer benefício, enquanto "irreversibilidade da decisão de terceirização", "problemas relacionados ao staff do contratante" e "questões de segurança" foram preteridos a todos os benefícios. 
Figura 3

Sobreposição das respostas de cada respondente

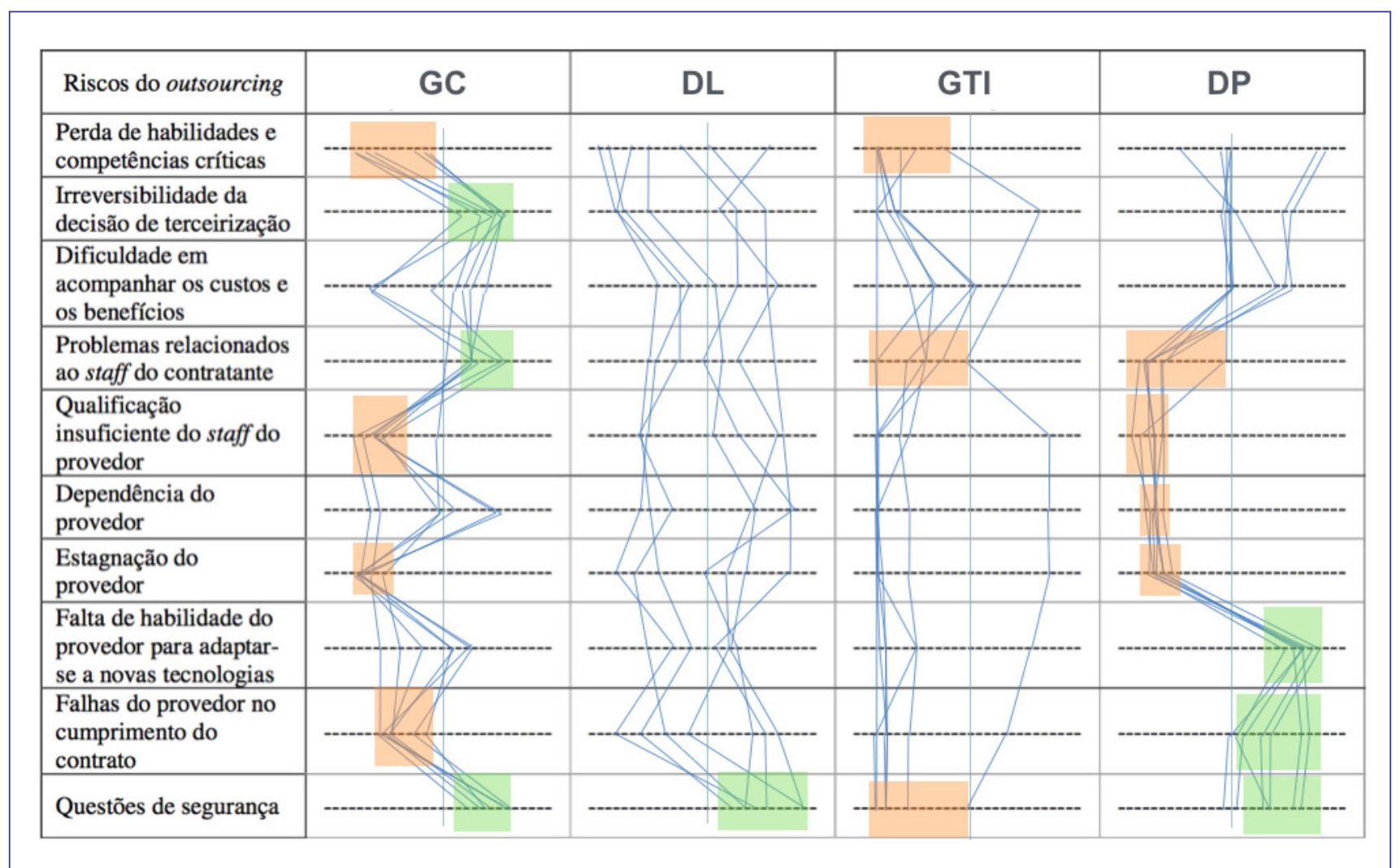

Fonte: Elaborada pelo autor.

Do gráfico DL infere-se que o risco "perda de habilidades e competências críticas" foi priorizado entre todos os benefícios, exceto "reduzir custos com tecnologia", enquanto o risco "questões de segurança" foi preterido a todos os benefícios. Os demais riscos foram priorizados em medida equivalente aos benefícios. Do gráfico GTI infere-se uma preocupação, e consequente priorização, dos riscos "perda de habilidades e competências críticas", "problemas relacionados ao staff do contratante" e "questões de segurança" perante qualquer benefício. Para esse respondente os demais riscos também foram priorizados entre todos os benefícios, exceto aquele relacionado a "focar a estratégia organizacional". Do gráfico DP infere-se uma priorização dos riscos "problemas relacionados ao staff do contratante", "qualificação insuficiente do staff do provedor", "dependência do provedor" e "estagnação do provedor" diante de qualquer benefício, enquanto os riscos "falta de habilidade do provedor para se adaptar a novas tecnologias", "falhas do provedor no cumprimento do contrato" e "questões de segurança" foram preteridos a todos os benefícios.

Depois da análise individualizada, fez-se a sobreposição dos gráficos finais de cada respondente em busca de convergências (Figura 3). O resultado permitiu inferências sobre: a) a preocupação de todos os respondentes com o risco "perda de habilidades e competências críticas", o que parece surpreendente, uma vez que a habilidade e a competência em gerir o conhecimento ainda não seriam um ativo das organizações contempladas no estudo; b) sobre as "questões de segurança" terem sido preteridas por todos os respondentes, exceto o GTI; e c) sobre a "estagnação do provedor" e "qualificação insuficiente do staff do provedor" serem preocupações relevantes, embora não unânimes. Da análise em grupo destacam-se ainda os pontos de divergência, ou seja, os riscos envolvidos com "dificuldade em acompanhar os custos e os benefícios", "dependência do provedor" e "falta de habilidade do provedor para se adaptar a novas tecnologias" não foram polarizados pelos respondentes na análise individual ou em grupo. 
Infere-se com base no quadro geral, exposto na Figura 3, que a opção pelo risco da gestão terceirizada do conhecimento esteve contida/restringida principalmente pelo receio da perda de habilidades e competências e pela inadequação do provedor em se atualizar e inovar constantemente. Embora não seja escopo desta pesquisa, é forçoso observarem-se evidências relativas à influência do perfil sociodemográfico dos gestores entrevistados sobre suas percepções e predisposições ao risco de implantação de mudanças na gestão, o que poderia ensejar estudos posteriores. Por exemplo, observa-se no gráfico GTI (o respondente mais experiente entre os entrevistados) uma tendência à priorização da análise dos riscos em detrimento dos benefícios, o que poderia estar associado a um perfil conservador, no sentido mesmo da busca por se evitar o risco.

A análise quantitativa do corpus sugere que: 1) na resposta à questão n. 2, em que os entrevistados expressaram opinião sobre a capacidade de um provedor externo conseguir manter o nível desejado de envolvimento da alta direção quanto às atividades de gestão de conhecimento, os respondentes tenderam a ser positivos, uma vez que foram quinze as declarações positivas, com apenas duas negativas; 2 ) nas respostas à questão seguinte, percebe-se que os respondentes não fazem objeção à participação do provedor nessa atividade; 3) nas respostas à questão n. 4 se destacaram as declarações condicionantes (em número de nove), e a ocorrência de um certo equilíbrio entre posicionamentos positivos e negativos, quantificando sete e quatro opiniões, respectivamente, o que conduz ao entendimento de que ainda há dúvidas ou ressalvas a serem consideradas em relação à capacidade de um provedor em manter o foco em uma ou, no máximo, duas prioridades estratégicas para o programa de gestão do conhecimento; 4) na questão seguinte infere-se, com base no número de declarações positivas, que os gestores se mostram simpáticos à situação proposta; entretanto, os trechos condicionantes (em número de seis) conferem restrições a essa opção; 5) para as respostas à questão n. 6, em que os entrevistados expressaram opinião sobre a vantagem que um provedor pode ter na identificação e na superação das barreiras impostas pelos detentores do conhecimento em relação aos colaboradores internos, percebe-se um equilíbrio nas opiniões, o que pode denotar insegurança em ser assertivo. Prevalecem as declarações condicionantes (em número de nove), ao passo que as declarações favoráveis (em número de sete) não são suficientes para suplantar as desfavoráveis (em número de cinco); 6) nas respostas à questão seguinte, que trata da influência que um provedor possa ter sobre a cultura organizacional da empresa contratante, se destacam as declarações desfavoráveis e condicionantes do DL a essa possibilidade. Os demais gestores não fizeram objeções; 7) as respostas à questão $n .8$ foram unânimes, de teor positivo, à participação de um provedor no planejamento e na distribuição de incentivos motivacionais aos colaboradores internos; 8) a questão de n. 9 apresentou elevado teor positivo nas respostas, mas com significativa presença de declarações condicionantes, a maioria emitida pelo DP, como se observa no trecho: "A gente fica a perguntar se realmente você vai conseguir a adesão da equipe para implantação dessas estratégias"; e 9) as respostas à última questão ratificaram o discurso que pode ser observado ao longo das falas: todos os gestores esperam que a terceirização da gestão do conhecimento seja uma etapa de um processo mais amplo, que culmina com o insourcing da atividade.

Em uma análise geral do corpus quantificado, percebeu-se tendência dos entrevistados a serem simpáticos às questões de outsourcing, uma vez que o estudo contabilizou 104 respostas favoráveis e 22 desfavoráveis. Destacam-se ainda os posicionamentos condicionantes (58), que superaram as opiniões negativas.

\section{DISCUSSÃO}

A pesquisa de um tema polêmico adiciona riscos consideráveis ao já não desprezível montante de riscos que ocorre na investigação em si. Ao se iniciar esta pesquisa, sabia-se a polêmica que dela poderia surgir, visto que significativa parcela da literatura defende reserva da execução de atividades próximas ao core business organizacional às suas áreas internas. De forma não generalizável, no entanto, a verificação empírica demonstrou abertura de representantes de setores específicos, restrita a seleto grupo de gestores, para discutir a terceirização da gestão do conhecimento.

A triangulação das técnicas de validação empírica e de análise dos resultados, por meio da busca de relações homogêneas entre as respostas, gráficos para visualização de padrões de respostas e análise de conteúdo, procurou adequar cada técnica aos construtos considerados e, com isso, obter a compreensão de cada respondente em relação ao tema, em momentos e por meio de instrumentos distintos e complementares. 
Assim, os achados indicam homogeneidade em relação à opção pela atuação do provedor na gestão do conhecimento. Em outros termos: os gestores entrevistados optariam pela terceirização da gestão do conhecimento, com atuação do provedor em todas as catorze dimensões dessa gestão, com maior concentração das respostas no nível "Seletivo", ou seja, entre 20\% e $80 \%$ daquelas dimensões, consoante os resultados encontrados em Huang, Miranda e Lee (2004, p. 317). No entanto, essa opção aparece condicionada à avaliação dos riscos. Todos os gestores demonstraram preocupação com o risco de "perda de habilidades e competências críticas", o que surpreende, uma vez que a habilidade e a competência em gerir o conhecimento ainda não é um ativo dessas organizações, mas, de outro lado, antecipa uma perspectiva discutida nas questões abertas e que recebeu confirmação positiva unânime: a terceirização da gestão do conhecimento deveria ser tratada como uma etapa, com duração prevista e negociada entre as partes, e com posterior insourcing da atividade.

Ainda sobre os riscos, é relevante destacar a pouca importância dada por três dos quatro gestores às "questões de segurança", o que corresponde aos achados de González, Gasco e Llopis (2010) e reforça a importância do estabelecimento de uma relação de confiança, resultante das interações, corroborando síntese de Edvardsson e Durst (2014) sobre a terceirização de processos de conhecimento (KPO) e de Ferguson, Huysman e Soekijad (2010) sobre o conhecimento aplicado a políticas públicas de desenvolvimento; da adoção de uma abordagem incorporada (network), na qual a confiança é suficiente para substituir as declarações formais em contrato (LEE, MIRANDA e KIM, 2004); e do alcance de um estágio de maturidade em outsourcing, em que os relacionamentos entre provedor e contratante podem reduzir a necessidade de monitoramento detalhado do desempenho do provedor pelo contratante (SOLLI, SAETHER e GOTTSCHALK, 2008).

Ademais, respostas às questões abertas indicam condicionantes que remetem às relações de confiança. São textos como "Eu acho que é um tema bem complexo, e que eu acho que tem que ser trabalhado sempre a quatro mãos", "Até que se conquiste a confiança da equipe" ou "Sim, sim, sim. Se sentir firmeza no provedor, sim", que reforçam a confiança como um pressuposto para que todo o processo de terceirização da gestão do conhecimento ocorra. Uma vez estabelecida essa relação baseada na confiança, parece que as questões de segurança se tornam secundárias.

A relevância das preocupações com os riscos de "estagnação do provedor" e "qualificação insuficiente do staff do provedor" corrobora a pesquisa de González, Gasco e Llopis (2010), que mesmo não sendo uma manifestação unânime, denota a expectativa de alto nível de especialização e inovação que se espera obter de um provedor (PALVIA, 1995; CULLEN, SEDDON e WILLCOCKS, 2005; HÄTÖNEN e ERIKSSON, 2008). Se essas questões inspiram incerteza sobre o desempenho futuro do provedor, diante dessa incerteza se buscará mitigar o risco adotando-se controles formais (HUANG, MIRANDA e LEE, 2004), o que está representado em falas dos gestores como: "Ela é contratada para aquilo", "(...) saber exatamente o que se está contratando" ou "(...) das expectativas de quem está contratando e das expectativas de quem for contratado".

A análise dos benefícios destacou o caso do respondente GTI, que demonstrou pouca inclinação a optar pelos riscos em relação a todos os benefícios expostos, à exceção do benefício "focar na estratégia organizacional". Tal posicionamento discrepa da maioria de suas declarações, quase sempre focadas no risco. Entretanto, em algumas de suas falas pode-se perceber sua preocupação com os riscos: "Eu confesso, posso dizer que abrir todo o conhecimento, armazenamento, conhecer tudo da empresa... há um risco aí latente". Destaca-se também a análise das respostas do DL, que demonstrou preferir plenamente os benefícios, quando se refere à "redução de custo com tecnologia" e "facilitar o acesso à tecnologia", a despeito de qualquer risco.

A análise das questões abertas mostra uma tendência favorável dos gestores à atuação do provedor no desenho, na execução e no controle do programa de gestão do conhecimento. A maioria de respostas com teor positivo confirma essa assunção, não obstante o nível significativo de situações condicionantes e de teor negativo. Os aspectos condicionantes inspiram cuidados quanto à: 1) capacidade do provedor externo em manter o foco em uma ou, no máximo, duas prioridades estratégicas, o que envolve desenho e execução; 2) identificação e superação das barreiras impostas pelos detentores do conhecimento, o que envolve execução e controle; 3) quanto à influência que o provedor possa ter sobre a cultura organizacional; e 4) possibilidade de um provedor aprimorar a capacidade estratégica da organização, estes últimos envolvendo desenho, execução e controle.

As questões com elevado teor negativo coincidem com as condicionantes, excetuando-se a questão que trata da possibilidade de um provedor aprimorar a capacidade estratégica da organização e adicionando-se a questão que trata da possibilidade 
de o provedor definir uma arquitetura completa para o programa de gestão do conhecimento, o que envolve todas as etapas (desenho, execução e controle) de atuação. Não houve ressalvas nas questões sobre a capacidade do provedor envolver e manter o nível desejado de envolvimento da alta direção, de participar do processo de definição de um objetivo específico de negócios e de participar do planejamento e da distribuição de incentivos motivacionais aos colaboradores internos.

Tal configuração de posicionamentos denota um baixo nível de maturidade (SOLLI, SAETHER e GOTTSCHALK, 2008) dos gestores quanto à terceirização, ao tempo em que reforçam causas conhecidas de insucesso de programas de gestão do conhecimento (LUCIER e TORSILIERI, 1997). Embora não tenham sido considerados negativamente, as condicionantes à possibilidade de um provedor aprimorar a capacidade estratégica da organização seguem na contramão das recomendações para que o outsourcing evolua, de um foco em atividades operacionais e táticas para um nível de ações estratégicas (WILLCOCKS, 2010; LACITY e WILLCOCKS, 2013).

Em resumo e fundamentalmente, as opiniões emitidas pelos gestores ratificam a relevância do conhecimento como diferencial competitivo em seus respectivos mercados, capaz de estabelecer condições favoráveis ao desenvolvimento de vantagens competitivas sustentadas, o que reforça o entendimento do conhecimento como um recurso de elevado valor (CONNER e PRAHALAD, 1996).

\section{CONSIDERAÇÕES FINAIS}

Este estudo assume como pressupostos que a) o conhecimento é recurso organizacional capaz de promover vantagem competitiva sustentada; b) gerir conhecimentos é decisão estratégica; e c) implantar efetiva gestão do conhecimento é tarefa complexa, que pode requerer apoio externo à organização. Tomando como ponto de partida esses pressupostos, o estudo procura resposta à questão: "É possível que gestores optem por terceirizar a gestão do conhecimento, uma vez que reconheçam dificuldades de realização dessa atividade só com recursos próprios?”. Ou seja, procura-se ampliar o limite das discussões que relacionam dois grandes temas: gestão do conhecimento e outsourcing, por meio de um termo comum: a terceirização da gestão do conhecimento, ou knowledge management outsourcing (KMO).

Tendo como orientações teóricas a RBV e a visão da firma baseada em conhecimentos (KBV), consultas a gestores sugerem que há possibilidade de opção pela terceirização como meio de implantação e operacionalização da gestão do conhecimento nas organizações consultadas. Essa opção é moderada pelo risco de perda de habilidades e competências críticas, o que sugere, na percepção dos gestores, que a terceirização da gestão do conhecimento deveria ser tratada como uma etapa, com duração prevista e negociada entre as partes, e com posterior insourcing da atividade.

Destaca-se também a importância do estabelecimento de relações de confiança, suficientes para substituir as declarações formais em contrato. Infere-se a necessidade de vivência/experiências mútuas, de modo que a longevidade da relação favoreça o estabelecimento de relações de confiança e o alcance de um estágio de maturidade em outsourcing, em que os relacionamentos entre provedor e contratante possam reduzir a necessidade de monitoramento detalhado do desempenho do provedor pelo contratante.

Do ponto de vista prático/gerencial, constatou-se entre os gestores oportunidade de difusão do tema, o que pode ser percebido com declarações espontâneas do tipo "Eu não tinha essa dimensão", "Realmente esse assunto é do momento, é uma preocupação nossa" ou "Eu vejo a terceirização nesse nível menos como uma questão de custos". Espera-se que a discussão contribua ainda para a geração de oportunidades de trabalho, por meio do desenvolvimento de empreendimentos voltados à oferta de serviços em terceirização da gestão do conhecimento (o modelo conceitual aqui proposto pode ser útil nesse sentido), mais que apenas consultoria em gestão do conhecimento.

Do ponto de vista teórico, observou-se que no relacionamento entre esses dois grandes temas (gestão do conhecimento e outsourcing) reside uma extrapolação de conceitos sedimentados como knowledge process outsourcing (KPO) e business process outsourcing (BPO). Essa extrapolação gera provocações sobre a assunção de que a terceirização seja apropriada apenas para áreas ou funções que possam ser suficientemente roteirizadas, descritas e compartimentadas em um escopo predefinido (TEIRLINK, DUMONT e SPITHOVEN, 2010). Afinal, não se encontra na literatura prescrições 
quanto a quão próximo do core business a terceirização possa ser aplicada (HÄTÖNEN e ERIKSSON, 2008; EDVARDSSON e DURST, 2014).

Parafraseando Cullen, Seddon e Willcocks (2005), o processo de outsourcing em si não seria nem bom, nem mau. O resultado obtido seria consequência de como o processo é gerido, antes e depois da assinatura do contrato.

\section{Limitações e estudos futuros}

Entre as limitações que podem afetar os resultados expostos, destaca-se o fato de os gestores convidados a participar deste estudo conhecerem pessoalmente este pesquisador. Relações pessoais e profissionais anteriores podem ter influenciado, positiva ou negativamente, a percepção das proposições feitas e as manifestações de opção. Ao mesmo tempo, embora este estudo tenha considerado percepções acerca de riscos, uma análise psicográfica e dos perfis de personalidade dos respondentes não foi feita. À medida que os gestores falam por sua organização, correr riscos pode estar sujeito às influências pessoais, culturais e da organização para a qual se trabalha. Estudos posteriores poderiam trabalhar essas questões como variáveis categóricas.

Nesse sentido, destacam-se também as recomendações para que se visite o núcleo da teoria do comportamento planejado (BENBASAT e BARKI, 2007) e se redirecione o foco para a análise de antecedentes e consequentes relacionados à terceirização. Pode-se, por exemplo, explorar o modelo de opção pela terceirização, baseado no modelo TAM (Technology Acceptance Model) (DAVIS, BAGOZZI e WARSHAW, 1989). Benamati e Rajkumar (2003), por exemplo, trabalham sobre os antecedentes TAM associados à terceirização, quais sejam: o ambiente externo, os relacionamentos prévios em terceirização e os riscos percebidos com a terceirização. 


\section{REFERÊNCIAS}

AHMED, P. K.; LIM, K. K.; ZAIRI, M. Measurement practice for knowledge management. Journal of Workplace Learning, v. 11, n. 8, p. 304-311, 1999.

ALAVI, M.; LEIDNER, D. E. Knowledge management and knowledge management systems: conceptual foundations and research issues. MIS Quartely, v. 25, n. 1, p. 107-136, 2001.

AMBROSIO, J. Knowledge management mistakes. Computerworld, 2000. Disponível em: <http://www.computerworld.com/article/2596225/vertical-it/knowledge-management-mistakes.html>. Acesso em: 16 fev. 2016.

ARGYRIS, C. Organizational learning and management information systems. Accounting, Organizations and Society, v. 2, n. 2, p. 113-123, 1977.

ARMISTEAD, C. Knowledge management and process performance. Journal of Knowledge Management, v. 3, n. 2, p. 143-154, 1999.

ASIEDU, E. A critical review on the various factors that influence successful implementation of knowledge management projects within organizations. International Journal of Economics \& Management Sciences, v. 4, n. 7, p. 1-5, 2015.

BARDIN, L. Análise de conteúdo. Lisboa: Ed. 70, 1977.

BENAMATI, J.; RAJKUMAR, T. An empirical study of the applicability of the technology acceptance model to application development outsourcing decisions. In: AMERICAS CONFERENCE ON INFORMATION SYSTEMS, 2003. Proceedings... [S.I]: [s.n], 2003.

BENBASAT, I.; BARKI, H. Quo vadis, TAM? Journal of the Association for Information Systems, v. 8, n. 4, p. 211-218. 2007.

BOSE, R. Knowledge management metrics. Industrial Management \& Data Systems, v. 104, n. 6, p. 45-468, 2004.

BURK, M. Knowledge management: everyone benefits by sharing information. Public Roads, v. 63, n. 3, p. 26-29, 1999.

BUSBIN, J. W.; JOHNSON, J. T.; DeCONINCK, J. The evolution of sustainable competitive advantage: from value chain to modular outsource networking. Competition Forum, v. 6, n. 1, p. 103-108, 2008.

CONNER, K.; PRAHALAD, C. A resource-based theory of the firm: knowledge versus opportunism. Organization Science, v. 7, n. 5, p. 477-501, 1996.

CULLEN, S.; SEDDON, P.; WILLCOCKS, L. Managing outsourcing: the life cycle imperative. MIS Quarterly Executive, v. 4, n. 1, p. 229-246, 2005

DALKIR, K. Knowledge management in theory and practice. Cambridge, MA: The MIT Press, 2011.

DAVENPORT, T.; PRUSAK, L. Working knowledge: how organizations manage what they know. Boston, MA: Harvard Business School Press, 1998.

DAVIS, F. D.; BAGOZZI, R. P.; WARSHAW, P. R. User acceptance of computer technology: a comparison of two theoretical models. Management Science, v. 35, n. 8, p. 982-1003, 1989.

DEMAREST, M. Understanding knowledge management. Long Range Planning, v. 30, n. 3, p. 374-384, 1997.

DIEDRICH, A.; GUZMAN, G. From implementation to appropriation: understanding knowledge management system development and introduction as a process of translation. Journal of Knowledge Management, v. 19, n. 6, p. 1273-1294, 2015.
DOSI, G.; NELSON, R.; WINTER, S. (Eds.). The nature and dynamics of organizational capabilities. Oxford: Oxford University Press, 2000.

EARL, M. J. The risks of outsourcing IT. Sloan Management Review, v. 37, n. 1, p. 26-32, 1996.

EDVARDSSON, I. R.; DURST, S. Outsourcing of knowledge processes: a literature review. Journal of Knowledge Management, v. 18, n. 4, p. 795-811, 2014.

FERGUSON, J.; HUYSMAN, M.; SOEKIJAD, M. Knowledge management in practice: pitfalls and potentials for development. World Development, v. 38, n. 12, p. 1797-1810, 2010.

FLEURY, M. T. L.; OLIVEIRA JR., M. M. Gestão estratégica do conhecimento: integrando aprendizagem, conhecimento e competências. São Paulo: Atlas, 2001

FONSECA, A. F. The effect of an integrated knowledge management architecture on organizational performance and impact: the case of The World Bank. College Park, MD: University of Maryland, 2003.

FONSECA, A. F. Organizational knowledge assessment methodology. Washington, DC: World Bank, 2006.

FRANCO, M. L. P. B. Análise de conteúdo. 2. ed. Brasília, DF: Liber Livro, 2007.

GARTNER. Gartner says worldwide IT outsourcing market to reach \$288 billion in 2013. 2013. Disponível em: <http://www.gartner.com/ newsroom/id/2550615>. Acesso em: 16 fev. 2016.

GOLDONI, V.; OLIVEIRA, M. Indicadores para a gestão do conhecimento na visão de especialistas. REAd, v. 13, n. 3, p. 478-501, 2007.

GONZALEZ, R.; GASCO, J.; LLOPIS, J. Information systems outsourcing risks: a study of large firms. Industrial Management \& Data Systems, v. 105, n. 1 , p. $45-62,2005$

GONZALEZ, R.; GASCO, J.; LLOPIS, J. Information systems outsourcing reasons and risks: a new assessment. Industrial Management \& Data Systems, v. 110, n. 2, p. 284-303, 2010.

GONZÁLEZ, A. J.; JOAQUÍ, C. Z.; COLLAZOS, C. A. Karagabi KMModel: modelo de referencia para la introducción de iniciativas de gestión del conocimiento en organizaciones basadas en conocimiento. Revista Chilena de Ingeniería, v. 17, n. 2, p. 223-235, 2009.

$\mathrm{GOO}$, J. et al. An investigation of factors that influence the duration of IT outsourcing relationships. Decision Support Systems, v. 42, n. 2, p. 2107-2125, 2007.

GOTZAMANI, K. D.; TSIOTRAS, G. D. The true motives behind ISO 9000 certification: their effect on the overall certification benefits and long term contribution towards TQM. International Journal of Quality and Reliability Management, v. 19, n. 2, p. 151-169, 2002.

GRANT, R. M. Toward a knowledge-based theory of the firm. Strategic Management Journal, v. 17, n. Special Issue, p. 109-122, 1996.

GROSSMAN, S. J.; HART, O. D. The costs and benefits of ownership: a theory of vertical and lateral integration. The Journal of Political Economy, v. 94, n. 4, p. 691-719, 1986.

GWET, K. L. Handbook of inter-rater reliability. 2. ed. Gaithersburg, MD: Advanced Analytics, 2010. 
HAMEL, G.; PRAHALAD, C. K. Corporate imagination and expeditionary marketing. Harvard business review, v. 69, n. 4, p. 81-92, 1990.

HÄTÖNEN, J.; ERIKSSON, T. 30+ years of research and practice of outsourcing: exploring the past and anticipating the future. Journal of International Management, v. 15, n. 2, p. 142-155, 2008.

HUANG, R.; MIRANDA, S.; LEE, J. How many vendors does it take to change a light bulb? Mitigating the risks of resource dependence in information technology outsourcing. In: ANNUAL INTERNATIONAL CONFERENCE ON INFORMATION SYSTEMS, 2004. Proceedings... [S.I]: [s.n], 2004.

IDM READER SURVEY. Where to for knowledge management in 2015: IDM reader survey. 2015. Disponível em: <http://www.idm.net.au/ article/0010488-where-knowledge-management-2015-idm-reader-survey>. Acesso em: 16 fev. 2016.

ISG. The ISG Outsourcing Index: global market data and insights. 2015. Disponível em: <http://docplayer.net/690757-The-isg-outsourcing-index-global-market-data-and-insights-second-quarter-and-first-half-2015-hosted-by-joe-foresi-janney-capital-markets.html>. Acesso em: 16 fev. 2016.

KAKABADSE, N. K.; KAKABADSE, A.; KOUZMIN, A. Reviewing the knowledge management literature: towards a taxonomy. Journal of Knowledge Management, v. 7, n. 4, p. 75-91, 2003.

KALAIGNANAM, K.; VARADARAJAN, R. Offshore outsourcing of customer relationship management: conceptual model and propositions. Journal of the Academy of Marketing Science, v. 40, n. 2, p. 347-363, 2012.

LACITY, M. C.; HIRSCHHEIM, R. The information systems outsourcing bandwagon. Sloan Management Review, v. 35, n. 1, p. 73-83, 1993.

LACITY, M. C.; WILLCOCKS, L. Legal process outsourcing: the provider landscape. Strategic Outsourcing: An International Journal, v. 6, n. 2, p. 167-183, 2013.

LAM, W.; CHUA, A. Knowledge management project abandonment: an exploratory examination of root causes. Communications of the Association for Information Systems, v. 16, n. 1, p. 723-743, 2005.

LEE, J. Exploring the vendor's process model in information technology outsourcing. Communications of the Association for Information Systems, v. 22, n. 1, p. 569-588, 2008.

LEE, J.; MIRANDA, S. M.; KIM, Y. IT outsourcing strategies: universalistic, contingency and configurational explanations of success. Information Systems Research, v. 15, n. 2, p. 110-131, 2004.

LIEBOWITZ, J.; MEGBOLUGBE, I. A set of frameworks to aid the project manager in conceptualizing and implementing knowledge management initiatives. International Journal of Project Management, v. 21, n. 3, p. 189-198, 2003.

LUCIER, C. E.; TORSILIERI, J. D. Why knowledge programs fail: a CEO's guide to managing learning. Strategy and Business, v. 9, $\mathrm{n}$. 4, p. 14-28, 1997.

MALHOTRA, Y. Why knowledge management systems fail: enablers and constraints of knowledge management in human enterprises. In: MCKEEN, J. D.; STAPLES, D. S. (Eds.). Handbook on knowledge management. Berlin: Springer-Verlag, 2004. v. 1. 577-599 p.

MALHOTRA, Y. Integrating knowledge management technologies in organizational business processes: getting real time enterprises to deliver real business performance. Journal of Knowledge Management, v. 9, n. 1, p. 7-27, 2005.

MARTINEZ-NOYA, A.; GARCIA-CANAL, E.; GUILLEN, M. F. R\&D outsourcing and the effectiveness of intangible investments: is proprietary core knowledge walking out of the door? Journal of Management Studies, v. 50, n. 1, p. 67-91, 2013.

NONAKA, I.: KROGH, G. Tacit knowledge and knowledge conversion: controversy and advancement in organizational knowledge creation theory. Organization Science, v. 20, n. 3, p. 635-652, 2009.

NONAKA, I.; TOYAMA, R.; HIRATA, T. Managing flow: a process theory of the knowledge-based firm. New York: Palgrave Macmillan, 2008.

O'BRIEN, J. A knowledge positioning framework of organizational groups. International Journal of Knowledge Engineering and Management, v. 3, n. 7, p. 1-22, 2015.

OLIVEIRA, M.; CALDEIRA, M.; ROMÃO, M. J. B. Knowledge management implementation: an evolutionary process in organizations. Knowledge and Process Management, v. 19, n. 1, p. 17-26, 2012.

PALVIA, P. C. A dialectic view of information systems outsourcing: pros and cons. Information \& Management, v. 29, n. 5, p. 265-275, 1995

POLANYI, M. The tacit dimension. London: Routledge/Kegan Paul, 1966.

POLLACK, J. Transferring knowledge about knowledge management: implementation of a complex organisational change programme. International Journal of Project Management, v. 30, n. 8, p. 877-886, 2012.

PORTER, M. Competitive advantage: creating and sustaining superior performance. New York: The Free Press, 1985.

PRUSAK, L. Where did knowledge management come from? IBM Systems Journal, v. 40, n. 4, p. 1002, 2001.

RUGGLES, R. The state of the notion: knowledge management in practice. California Management Review, v. 40, n. 3, p. 80-89, 1998.

SADEGHI, M. R.; MOGHIMI, S. M.; RAMEZAN, M. Identifying and prioritizing of effective constructs in readiness of knowledge management implementation by using fuzzy analytic hierarchy process (AHP). Journal of Knowledge-Based Innovation in China, v. 5, n. 1, p. 16-31, 2013.

SOLLI-SAETHER, H.; GOTTSCHALK, P. Maturity in IT outsourcing relationships: an exploratory study of client companies. Industrial Management \& Data Systems, v. 108, n. 5, p. 635-649, 2008.

SOUZA, L. L. C.; MALDONADO, M. U.; RADOS, G. J. V. Gestão da terceirização no setor brasileiro de distribuição de energia elétrica. RAE, v. 51, n. 2, p. 188-201, 2011.

SPENDER, J. C. Gerenciando sistemas de conhecimento. In: FLEURY, M. T. L.; OLIVEIRA JR., M. M. (Org.). Gestão estratégica do conhecimento: integrando aprendizagem, conhecimento e competências. São Paulo: Atlas, 2001

SPENDER, J. C.; SCHERER, A. G. The philosophical foundations of knowledge management. Organisation, v. 14, n. 1, p. 5-28, 2007.

TAKEUCHI, H.; NONAKA, I. Gestão do conhecimento. Porto Alegre: Bookman, 2008.

TEIRLINK, P.; DUMONT, M.; SPITHOVEN, A. Corporate decision-making in R\&D outsourcing and the impact on internal R\&D employment intensity. Industrial and Corporate Change, v. 19, n. 6, p. 1741-1768, 2010. 
TRIANTAPHYLLOU, E. et al. Multi-criteria decision making: an operations research approach. Encyclopedia of Electrical and Electronics Engineering, v. 15, p. 175-186, 1998.

TRIST, E. Introduction. In: TRIST, E.; MURRAY, H. (Eds.). The social engagement of social science: a Tavistock anthology. The socio-technical perspective. Philadelphia, PA: University of Pennsylvania Press, 1993. v. 2. 36-60 p.

VIEIRA, A. S. Monitoração da competitividade científica e tecnológica dos estados brasileiros. Um instrumento de macropolítica de informação. Ciência da Informação, v. 28, n. 2, p. 174-189, 1999.
WILLCOCKS, L. The next step for the CEO: moving IT-enabled services outsourcing to the strategic agenda. Strategic Outsourcing: An International Journal. v. 3, n. 1, p. 62-66, 2010.

WONG, K. Y. Critical success factors for implementing knowledge management in small and medium enterprises. Industrial Management \& Data Systems, v. 105, n. 3, p. 261-279, 2005.

WONG, K. Y.; ASPINWALL, E. Knowledge management implementation frameworks: a review. Knowledge and Process Management, v. 11, n. 2, p. 93-104, 2004. 


\title{
APÊNDICES
}

\author{
Formulário I \\ FORMULÁRIO DE AVALIAÇÃO DA OPÇÃO PELA GESTÃO TERCEIRIZADA DO CONHECIMENTO
}

\section{Identificação do respondente}

Nome

Organização

Cargo

Data

\section{Formulário}

Por favor, marque as células em branco com um caractere " $X$ ", de acordo com a medida em que você optaria pela atuação de uma empresa terceirizada (provedor) em cada área (dimensão) da gestão do conhecimento na sua organização. Caso haja dúvidas quanto aos conceitos utilizados, favor consultar o glossário, na página seguinte deste documento.

\begin{tabular}{|c|c|c|c|c|c|}
\hline & & \multicolumn{4}{|c|}{ Medida de opção pela atuação do provedor } \\
\hline \multicolumn{2}{|c|}{ Dimensões da gestão do conhecimento } & Nenhuma & Mínima & Seletiva & Compreensiva \\
\hline \multirow{5}{*}{ Pessoas } & Cultura e incentivos & & & & \\
\hline & Identificação e criação & & & & \\
\hline & Compartilhamento & & & & \\
\hline & $\begin{array}{l}\text { Comunidades de prática e equipes } \\
\text { de conhecimento }\end{array}$ & & & & \\
\hline & Aprendizado e absorção & & & & \\
\hline \multirow{5}{*}{ Processos } & Liderança e estratégia & & & & \\
\hline & $\begin{array}{l}\text { Alinhamento aos objetivos da } \\
\text { organização }\end{array}$ & & & & \\
\hline & $\begin{array}{l}\text { Operacionalização de processos } \\
\text { do conhecimento nos processos } \\
\text { institucionais }\end{array}$ & & & & \\
\hline & Fluxos de conhecimento & & & & \\
\hline & Medição e monitoramento & & & & \\
\hline \multirow{4}{*}{ Tecnologias } & $\begin{array}{l}\text { Tecnologia da Informação de } \\
\text { suporte às atividades e Programas } \\
\text { de Gestão do Conhecimento }\end{array}$ & & & & \\
\hline & $\begin{array}{l}\text { Infraestrutura de acesso ao } \\
\text { conhecimento }\end{array}$ & & & & \\
\hline & Gerenciamento de conteúdos & & & & \\
\hline & $\begin{array}{l}\text { Infraestrutura de suporte } \\
\text { ao Programa de Gestão do } \\
\text { Conhecimento }\end{array}$ & & & & \\
\hline
\end{tabular}

Fonte: Elaborado pelo autor. 


\section{GLOSSÁRIO}

Cultura e incentivos: atuação junto às atitudes, crenças e incentivos, implícitos e explícitos, que existem para moldar, criar e apoiar o uso de ativos intelectuais, inclusive conhecimento, para que as pessoas busquem atingir as metas organizacionais.

Identificação e criação de conhecimento: atuação nos processos criativos de conhecimento e demais ativos intelectuais, especialmente aqueles que contribuem para o alcance das metas organizacionais, buscando identificá-los para posterior utilização na organização.

Compartilhamento do conhecimento: esforços para que o conhecimento gerado seja compartilhado e contribua para o alcance das metas organizacionais.

Comunidades de prática e equipes de conhecimento: fomento à criação de grupos de pessoas que possam efetivamente atuar na solução de problemas. Atuação junto à criação, manutenção e disseminação desses grupos na organização.

Aprendizado e absorção: contribuição para que a organização amplie sua capacidade de construir capital intelectual humano, pela adoção de treinamentos e outras atividades formais de construção do conhecimento.

Liderança e estratégia: atuação junto aos gestores para que a gestão do conhecimento seja adotada e executada como um princípio de gestão.

Alinhamento aos objetivos da organização: atuação para que os resultados da implantação da gestão do conhecimento estejam voltados ao alcance das metas organizacionais.

Operacionalização de processos do conhecimento nos processos institucionais: atuação na integração e aplicação do conhecimento aos processos operacionais, seja na criação de novos produtos, planejamento de marketing, seja na solução de problemas do dia a dia. Essa dimensão corresponde essencialmente ao fechamento do ciclo da gestão do conhecimento, quando esse conhecimento é (re)inserido nos processos centrais de negócio e, assim, contribui com a geração de resultados para a organização.

Fluxos de conhecimento: atuação na ampliação da capacidade de circulação do conhecimento dentro da organização. Inclui captura, armazenamento e disseminação do conhecimento.

Medição e monitoramento: atuação na ampliação da capacidade da organização de medir sua própria performance com respeito à gestão dos ativos intelectuais, bem como no monitoramento e na identificação das melhores práticas que permitam o aprendizado contínuo.

Tecnologia da Informação de suporte às atividades e Programas de Gestão do Conhecimento: atuação junto à área técnica para que haja infraestrutura capacitada para lastrear as atividades de gestão do conhecimento na organização.

Infraestrutura de acesso ao conhecimento: atuação junto à disseminação da infraestrutura de TI para que os ativos intelectuais estejam disponíveis e acessíveis a todos os stakeholders no momento oportuno.

Gerenciamento de conteúdos: atuação junto à gestão dos tipos de conteúdo e ferramentas de gerenciamento da informação que a organização manipula na execução da sua gestão do conhecimento.

Infraestrutura de suporte ao Programa de Gestão do Conhecimento: atuação no planejamento do programa de gestão do conhecimento da organização, envolvendo as pessoas que participarão, as unidades/setores envolvidos, a tecnologia adotada etc.

Medida de opção pela atuação da terceirizada: define o grau em que a empresa terceirizada para gerir o conhecimento na sua organização poderia atuar em cada dimensão do processo (de gestão de conhecimento).

- Nenhuma: não opta pela atuação da terceirizada naquela dimensão;

- Mínima: opta por atuação discreta, com percentual de contratação da(s) empresa(s) terceirizada(s) abaixo de $20 \%$ do orçamento total para a área de Tl;

- Seletiva: opta por atuação moderada, com percentual de contratação da(s) empresa(s) terceirizada(s) entre 20 e $80 \%$ do orçamento total para a área de Tl; e

- Compreensiva: opta por forte atuação, com percentual de contratação da(s) empresa(s) terceirizada(s) acima de $80 \%$ do orçamento total para a área de TI. 


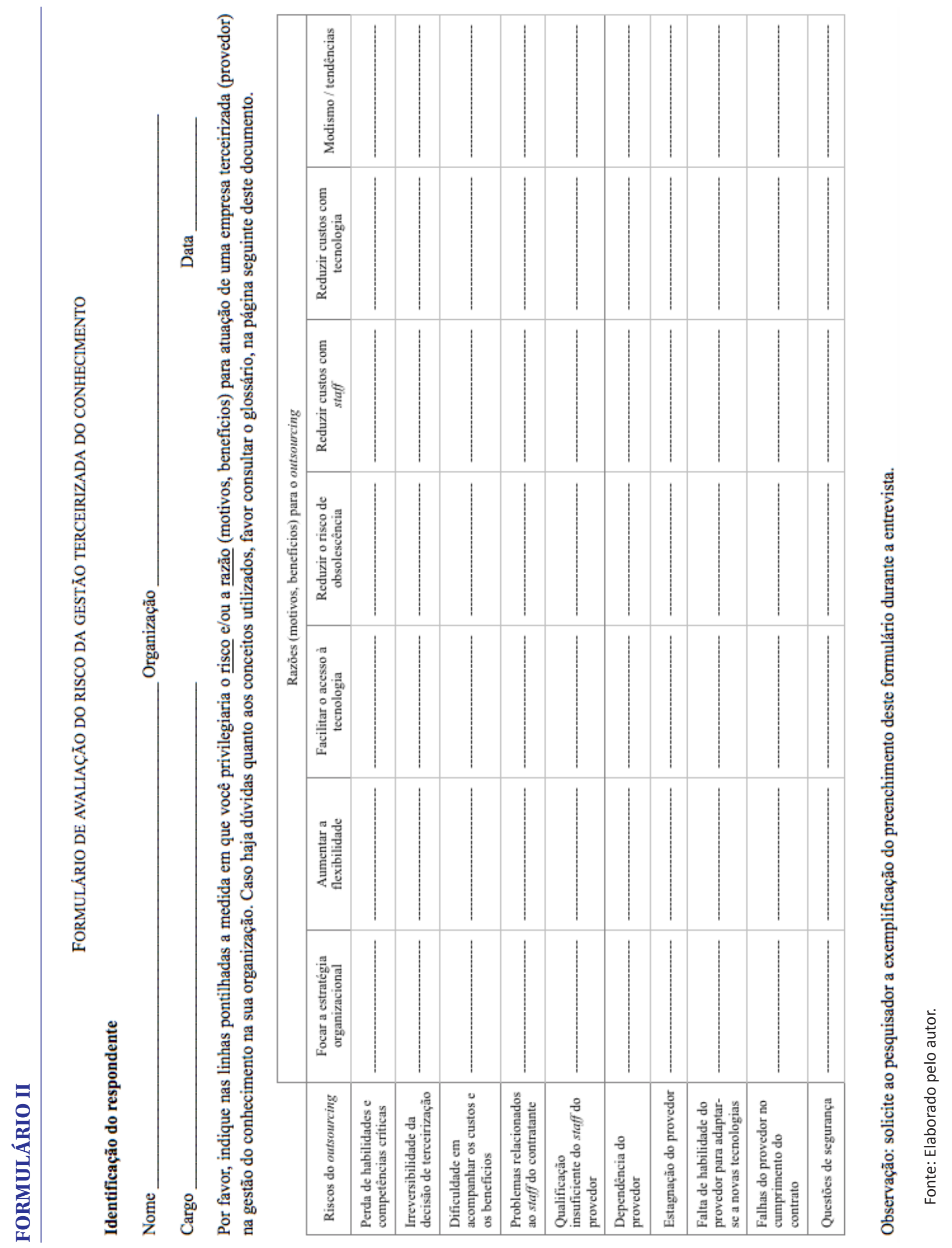




\section{Glossário}

Dependência do provedor: parte da dificuldade que o contratante tem de identificar, definir e quantificar os serviços necessários. Além disso, os serviços evoluem com o tempo, o que pode representar aditivos contratuais e respectivos custos.

Estagnação do provedor: A evolução necessária na área terceirizada é negligenciada. Isso pode ocorrer porque os provedores externos não são parceiros estratégicos e tendem a se preocupar com o seu próprio lucro, mais do que com o sucesso da operação do contratante.

Perda de habilidades e competências críticas: mesmo quando o provedor oferece serviços inovadores para o contratante, boa parte dos novos conhecimentos permanece com o provedor.

Qualificação insuficiente do staff do provedor: pode ocorrer inclusive o repasse de quadros técnicos do contratante para o provedor, o que mantém a qualificação nos mesmos níveis anteriores à terceirização.

Falhas do provedor no cumprimento do contrato: má interpretação de prioridades, prazos, foco etc.

Dificuldade do contratante em acompanhar os custos e os benefícios da terceirização: além da dificuldade em gerar métricas de monitoramento, a terceirização pode ter custos obscuros, decorrentes de falhas nas especificações, turnover no staff terceirizado, mudança de provedor, custos de gerenciamento da terceirização e custos com a reinternalização dos serviços.

Questões de segurança: necessidade de negociação dos níveis de confidencialidade das informações manipuladas durante a prestação do serviço, a serem mantidos pelo provedor.

Irreversibilidade da decisão de terceirização: principalmente quando o contratante perde sua infraestrutura técnica e humana para a execução do serviço.

Problemas relacionados ao staff do contratante: as pessoas podem ver a terceirização como uma ameaça a seu emprego ou à sua posição atual na empresa. Isso pode levar à perda de produtividade, mesmo que temporária.

Falta de habilidade do provedor para se adaptar a novas tecnologias: se o esforço para a atualização tecnológica não for recompensado pelas margens de lucro, o provedor pode tentar manter a tecnologia e os processos sem evolução.

Foco na estratégia organizacional: a terceirização é uma das principais maneiras de fazer com que a organização dirija seus esforços para suas competências essenciais.

Aumento de flexibilidade: as empresas podem usar a terceirização como estratégia para serem mais flexíveis, durante reestruturações e reorganizações internas de processos.

Facilidade de acesso à tecnologia: a terceirização contribui para a redução da necessidade de investimentos em tecnologia, ao mesmo tempo que incrementa a disponibilidade de novas tecnologias para a empresa contratante.

Redução do risco de obsolescência: o risco de prospecção e investimento em novas tecnologias é do provedor. A necessidade de atualização constante nessas novas tecnologias também.

Redução de custos com staff: os custos com seleção, contratação e eventuais demissões de pessoal ficam a cargo do provedor. A necessidade de gerenciamento de pessoal também, bem como a capacitação constante para manutenção de perfis altamente especializados.

Redução dos custos com tecnologia: as tecnologias requerem grandes investimentos per se. Isso envolve expertises, habilidades e toda a infraestrutura necessária a seu funcionamento. Os provedores obtêm economia de escala em suas instalações e isso é repassado ao contratante como um diferencial em relação ao insource.

Modismo/tendências: algumas empresas optam pela terceirização como mecanismo mimético em relação a outras que demonstraram, previamente, ser bem-sucedidas em suas experiências de terceirização. Esse não é um argumento desprezível e pode estar encoberto por outros argumentos. 


\section{Questões abertas}

1. A sua empresa pratica ou praticou algum tipo de terceirização? Há quanto tempo? Você participou do processo?

2. Você acredita que um provedor externo consiga envolver e manter o nível desejado de envolvimento da alta direção com as atividades de gestão do conhecimento?

3. Você acredita que um provedor externo possa participar de um processo de definição de um objetivo específico de negócios para a implantação da gestão do conhecimento?

4. Você acredita que um provedor externo seja capaz de manter o foco em uma ou, no máximo, duas prioridades estratégicas para o programa de gestão do conhecimento, em suas etapas iniciais de implantação?

5. Você acredita que um provedor externo possa definir uma arquitetura completa para o programa de gestão do conhecimento, mesmo que essa arquitetura seja implantada gradativamente depois de ter sido definida?

6. Você acredita que um provedor externo possa ter mais chances de identificar e superar as barreiras impostas pelos detentores do conhecimento, ao seu compartilhamento, do que colaboradores internos?

7. Você acredita que um provedor externo possa influenciar sua cultura organizacional, a ponto de fazer com que as atividades de gestão do conhecimento sejam incorporadas culturalmente?

8. Você acredita que um provedor externo possa participar do planejamento e da distribuição de incentivos motivacionais aos colaboradores internos, como parte do programa de gestão do conhecimento?

9. Você acredita que um provedor externo possa aprimorar a capacidade estratégica da sua organização, ao participar/promover atividades de inovação (processos, habilidades, tecnologias) e de transformação organizacional?

10. Uma vez evidenciados os benefícios do conhecimento para a organização, você acredita que a atividade de gestão desse conhecimento possa ser internalizada (promovendo o encerramento da terceirização)?

11. Você colocaria (ou se esforçaria para colocar) sua organização à disposição para um teste piloto de terceirização da gestão do conhecimento?

\section{Fontes para as questões abertas:}

1. Inserida pelo pesquisador;

2. "Top management sponsorship without active, ongoing involvement", Lucier e Torsilieri (1997, p. 15);

3. "No specific business objective, but only general aspirations like 'share best practices' or 'stimulate collaboration", Lucier e Torsilieri (1997, p. 15);

4. "Insufficient focus upon one or two strategic priorities", Lucier e Torsilieri (1997, p. 15); "Start with a focused pilot project", Davenport e Prusak (1998, p. 162);

5. "Incomplete program architecture", Lucier e Torsilieri (1997, p. 15);

6. "Knowledge transfer", Davenport e Prusak (1998, p. 88);

7. "Improve knowledge culture and enviroments", "A knowledge oriented-culture", Davenport e Prusak (1998, p. 144);

8. "People rarely give away valuable possessions, including knowledge, without expecting something in return", "The use of evaluation and compensation systems to change behavior", "Non trivial motivational aids", Davenport e Prusak (1998, p. 25, 144);

9. "enhance strategic capabilities by partnering with a complementary supplier", Willcocks (2010, p. 65);

10. Inserida pelo pesquisador;

11. Inserida pelo pesquisador. 


\section{Rationale para a seleção de itens de mensuração relacionados a riscos (Formulário II):}

Uma área ou função da organização será terceirizada se sua contribuição para a dimensão do desempenho organizacional for baixa e o custo ou a qualidade geram problemas de economia de escala (EARL, 1996, tradução nossa). Earl (1996) afirma que existem onze tipos de riscos na terceirização, identificados em conversas com fornecedores e consumidores (de outsourcing):

1. Possibilidade de fraca gestão/gerenciamento: gerenciar terceiros está longe de ser uma tarefa fácil. A organização optará por contratar bons gerentes ou postergar a terceirização até que tenha condições de gerenciá-la adequadamente. Isso significa que antes de pensar em terceirizar, a organização deve ser capaz de gerenciar por si o serviço.

2. Staff sem experiência: provedores de serviços terceirizados nem sempre têm sólida experiência na atividade ou, ainda, seu pessoal nem sempre tem a melhor expertise. Se há, portanto, o risco de se contratar uma empresa sem experiência, há ainda o risco de perder funcionários bem capacitados para a própria empresa contratada.

3. Incerteza nos negócios: A terceirização feita com o objetivo de redução de custos ou por mudança de foco deve considerar a direção estratégica da organização. Contratos de terceirização de longo prazo podem envolver a perda de capacidades e competências essenciais, como pessoal e processos operacionais.

4. Habilidades tecnológicas "datadas": há o risco de se contratar um provedor de serviços terceirizado cujo pessoal tem habilidades para atuação com tecnologias legadas interessantes no momento, mas que podem ficar defasadas a curto prazo. O contratante busca redução de custos, mas, se o provedor contratado não evoluir os conhecimentos, essa redução de custos pode não ser mantida ao longo do contrato, pois pode requerer contratações adicionais. O contratante também pode buscar foco, ou seja, dedicar-se à sua atividade central, terceirizando as demais atividades complementares. Nesse caso, a ineficiência causada pela desatualização de conhecimentos do provedor acabará por gerar perdas financeiras a longo prazo.

5. Incerteza endêmica: contratos terceirizados inerentemente envolvem incertezas. As especificações nem sempre são completas e/ou mudam com freqüência. Isso também ocorre com os requerimentos de operação. Decorrente disso, as revisões de cláusulas contratuais são constantes, com revisões anuais que acabam oferecendo certa flexibilidade, mas não sem um custo correspondente.

6. Custos invisíveis: a contratação de um terceiro é normalmente feita com base na comparação dos custos atuais. No entanto, os custos com o setup da operação (configurações iniciais necessárias como realocação, paralelismo etc.) e os custos com o gerenciamento da terceirização em si são frequentemente subestimados ou mesmo esquecidos.

7. Falta de aprendizagem organizacional: as organizações tendem a aprender a gerenciar fazendo. A perda da capacidade estratégica pode ser comprometida com a atuação de terceiros em áreas estratégicas ou com potencial de virem a ser.

8. Perda da capacidade de inovar: uma organização que tenha terceirizado determinada função, pode comprometer sua capacidade inovadora naquela área. Inovação requer recursos disponíveis, processos orgânicos e fluidos e competências experimentais e empreendedoras. Essas características nem sempre são possíveis de se obter em contratos terceirizados.

9. Perigos de um triângulo eterno: a função terceirizada nem sempre se relaciona diretamente com as funções internas associadas. Há com frequência a necessidade de um interlocutor, normalmente parte da função original, que atua como mediador das relações entre contratante e provedor contratado, pelo menos durante certo tempo.

10. Indivisibilidade tecnológica: enquanto algumas funções são plenamente passíveis de terceirização, podendo ser controladas por benchmarking, contratos de níveis de serviço (SLA, na sigla em inglês), incentivos de produtividade e revisões anuais, muitas outras funções são de difícil separação entre insource e outsourcing, devido à sua elevada integração ou interconexão, o que pode acarretar problemas de responsabilidade entre os domínios de provedores (se mais de um envolvido) ou do provedor com o contratante.

11. Foco difuso: o problema real com a terceirização é que ela tem se concentrado no "como" e não no "o quê", focando no suprimento e não na demanda, o que acaba por gerar mais necessidade de gerenciamento do que criação de receitas. 
Esses riscos não ocorrem em todas as situações de terceirização, mas não são incomuns (EARL, 1996). Alguns podem ser evitados ou reduzidos com gerenciamento adequado e cuidadosa seleção do provedor (o que é corroborado por SOUZA, MALDONADO e RADOS, 2011). No entanto, se a avaliação dos resultados com a terceirização versus. os riscos envolvidos forem desfavoráveis, haverá uma tendência à terceirização apenas das funções consideradas commodities.

Os riscos, segundo Gonzalez, Gasco e Llopis (2005; 2010), envolvem:

1. A dependência que a terceirização gera: parte da dificuldade que o contratante tem de identificar, definir e quantificar os serviços necessários. Além disso, os serviços evoluem com o tempo, o que pode representar aditivos contratuais e respectivos custos.

2. A evolução necessária na área terceirizada é negligenciada: isso pode ocorrer porque os provedores externos não são parceiros estratégicos e tendem a se preocupar com seu próprio lucro, mais do que com o sucesso da operação do contratante.

3. A perda de habilidades e competências críticas: mesmo quando o provedor oferece serviços inovadores para o contratante, boa parte dos novos conhecimentos permanece com o provedor.

4. Qualificação insuficiente do staff do provedor: pode ocorrer inclusive o repasse de quadros técnicos do contratante para o provedor, o que mantém a qualificação nos mesmos níveis anteriores à terceirização;

5. Falhas do provedor no cumprimento do contrato: má interpretação de prioridades, prazos, foco etc.

6. Dificuldade do contratante em acompanhar os custos e os benefícios da terceirização: além da dificuldade em gerar métricas de monitoramento, a terceirização pode ter custos obscuros, decorrentes de falhas nas especificações, turnover no staff terceirizado, mudança de provedor, custos de gerenciamento da terceirização e custos com o insourcing dos serviços.

7. Questões de segurança: necessidade de negociação dos níveis de confidencialidade das informações manipuladas durante a prestação do serviço, a serem mantidos pelo provedor.

8. Irreversibilidade da decisão de terceirização: principalmente quando o contratante perde a sua infraestrutura técnica e humana para a execução do serviço.

9. Problemas relacionados ao staff do contratante: as pessoas podem ver a terceirização como uma ameaça a seu emprego ou à sua posição atual na empresa. Isso pode levar à perda de produtividade, mesmo que temporária.

10. Falta de habilidade do provedor para se adaptar a novas tecnologias: se o esforço para a atualização tecnológica não for recompensado pelas margens de lucro, o provedor pode tentar manter a tecnologia e os processos sem evolução.

Há nove fatores principais de sucesso em projetos de implantação da gestão do conhecimento, segundo Davenport e Prusak (1998):

1. Cultura orientada ao conhecimento;

2. Infraestrutura técnica e organizacional;

3. Apoio/suporte aos gerentes sêniores;

4. Vínculos com valores econômicos e/ou da indústria da qual participa a organização;

5. Nível mínimo de orientação a processos;

6. Claridade de visão e linguagem;

7. Incentivos motivacionais não triviais;

8. Algum nível de estrutura de conhecimentos e

9. Múltiplos canais de transferência de conhecimentos.

Pedro Jácome de Moura Jr.

Doutor em Administração com ênfase em Tecnologia da Informação; Professor Adjunto no Departamento de Administração (DA/CCSA/UFPB)

E-mail: pjacome@sti.ufpb.br 